\title{
A physiologically based pharmacokinetic model of voriconazole integrating time-dependent inhibition of CYP3A4, genetic polymorphisms of CYP2C19 and predictions of drug-drug interactions
}

\section{Li, Xia}

2020-06

Li , X, Frechen, S , Moj, D , Lehr , T, Taubert , M , Hsin , S, Mikus , G, Neuvonen , P J , Olkkola , K , Saari , T \& Fuhr , U 2020 , ' A physiologically based pharmacokinetic model of voriconazole integrating time-dependent inhibition of CYP3A4, genetic polymorphisms of CYP2C19 and predictions of drug-drug interactions ' , Clinical Pharmacokinetics, vol. 59 , no. 6 , pp. 781-808 . https://doi.org/10.1007/s40262-019-00856-z

http://hdl.handle.net/10138/323512

https://doi.org/10.1007/s40262-019-00856-z

unspecified

acceptedVersion

Downloaded from Helda, University of Helsinki institutional repository.

This is an electronic reprint of the original article.

This reprint may differ from the original in pagination and typographic detail.

Please cite the original version. 
1 A Physiologically-Based Pharmacokinetic Model of Voriconazole 2 Integrating Mechanism-based Inhibition of CYP3A4, Genetic 3 Polymorphisms of CYP2C19 and Predictions of Drug-Drug Interactions

$5 \quad \mathrm{Xia} \mathrm{Li}^{1}$, Sebastian Frechen ${ }^{2}$, Daniel Moj ${ }^{3}$, Thorsten Lehr ${ }^{3}$, Max Taubert ${ }^{1}$, Chih-hsuan

1 University of Cologne, Faculty of Medicine and University Hospital Cologne, Center for Pharmacology, Department I of Pharmacology; Cologne, Germany;

2 Clinical Pharmacometrics, Bayer AG; Leverkusen, Germany;

3 Department of Pharmacy, Clinical Pharmacy, Saarland University; Saarbrücken, Germany;

4 Department of Clinical Pharmacology and Pharmacoepidemiology, University of Heidelberg; Heidelberg, Germany;

5 Department of Clinical Pharmacology, University of Helsinki and Helsinki University Hospital; Helsinki, Finland;

6 Department of Anaesthesiology, Intensive Care and Pain Medicine, University of Helsinki and Helsinki University Hospital, Helsinki, Finland;

7 Department of Anaesthesiology and Intensive Care, University of Turku and Turku University Hospital; Turku, Finland.

\section{Corresponding author:}

Univ.-Prof. Dr. med. Uwe Fuhr

University of Cologne, Faculty of Medicine and University Hospital Cologne, Center for Pharmacology, Department I of Pharmacology; Gleueler Straße 24, 50931 Cologne, Germany

Email: uwe.fuhr@uk-koeln.de

Tel: +49-(0)-221-478-6672 (office), -5230 (direct line)

Fax: +49-(0)-221-478-7011 
Background: Voriconazole, a first-line anti-fungal drug, exhibits nonlinear pharmacokinetics together with large inter-individual variability but a narrow therapeutic range, and it markedly inhibits CYP3A4 in vivo. This causes difficulties in selecting appropriate dosing regimens of voriconazole and of co-administered CYP3A4 substrates.

Objective: This study aimed to investigate the metabolism of voriconazole in detail to better understand doseand time-dependent alterations in the pharmacokinetics of the drug, to provide the model basis for safe and effective use according to CYP2C19 genotype, and to assess the potential of voriconazole to cause drug-drug interactions (DDIs) with CYP3A4 substrates in more detail.

Methods: In vitro assays were carried out to describe mechanism-based inactivation (MBI) of CYP3A4 by voriconazole. These results were combined with 93 published concentration-time curves of voriconazole from clinical trials in healthy volunteers to develop a whole-body physiologically-based pharmacokinetic (PBPK) model in PK-Sim ${ }^{\circledR}$. The model was evaluated quantitatively with the predicted/observed ratio of AUC, $\mathrm{C}_{\max }$, and $\mathrm{C}_{\text {trough, }}$ the geometric mean fold error, as well as visually with the comparison of predicted with observed concentration-time profiles over the full range of recommended intravenous and oral dosage regimens.

Results: The result of the $\mathrm{IC}_{50}$ shift assay indicated that voriconazole causes MBI of CYP3A4. The PBPK model evaluation demonstrated a good performance of the model, with $71 \%$ of predicted/observed aggregate AUC ratios and all aggregate $\mathrm{C}_{\max }$ ratios from 28 evaluation datasets being within a 0.5 - to 2 -fold range. For those studies reporting CYP2C19 genotype, $89 \%$ of aggregate AUC ratios and all aggregate $\mathrm{C}_{\max }$ ratios were inside a 0.5 - to 2 -fold range of 44 test profiles. The model suggests that the standard maintenance dose of $200 \mathrm{mg}$ bid is sufficient for CYP2C19 IMs (intermediate metabolizers: $* 1 / * 2, * 1 / * 3, * 2 / * 17$, and $* 2 / * 2 / * 17$ ) to reach the tentative therapeutic range of $>1-2 \mathrm{mg} / \mathrm{L}$ to $<5-6 \mathrm{mg} / \mathrm{L}$ for trough values, while $400 \mathrm{mg}$ might be more suitable for RMs (rapid metabolizers: $* 1 / * 17, * 17 / * 17$ ) and NMs (normal metabolizers, $* 1 / * 1$ ). When the model was integrated with independently developed CYP3A4 substrate models (midazolam and alfentanil), the observed AUC change of substrates by voriconazole was inside the $90 \%$ confidence interval of the predicted AUC change, indicating that CYP3A4 inhibition was appropriately incorporated into the voriconazole model.

Conclusions: Both the in vitro assay and model-based simulations confirmed MBI of CYP3A4 by voriconazole as a pivotal characteristic of this drug's pharmacokinetics. The PBPK model developed here could support individual dose adjustment of voriconazole according to genetic polymorphisms of CYP2C19, and DDI risk management. 
57

\section{Key Points:}

1. A whole-body physiologically-based pharmacokinetic (PBPK) model of voriconazole incorporating mechanism-based inhibition of CYP3A4 was successfully developed to accurately capture the time- and dose-dependent alterations of voriconazole pharmacokinetics for different CYP2C19 genotypes.

2. Model-based simulations could i) elaborate potential exposure-equivalent dosing regimens for CYP2C19 genotype groups; ii) assess the dynamic inhibition of CYP3A4 by voriconazole in the liver and small intestine; iii) predict DDIs between voriconazole and other CYP3A4 substrates. 


\section{INTRODUCTION}

Voriconazole is an essential drug in the treatment of severe fungal infections due to its activity against a wide range of clinically relevant fungal pathogens, including the most commonly occurring species of the genera Aspergillus and Candida, and some emerging fungi, such as Scedosporium and Fusarium species [1]. Moreover, voriconazole is well established as first-line therapy for patients with invasive aspergillosis [2-4]. However, the drug exhibits nonlinear pharmacokinetics with large inter-individual and intra-individual variability $[5,6]$, which causes difficulties for clinicians to choose appropriate dosing regimens to target its narrow therapeutic range, especially in the case of high doses in severe infections, or for chronic treatments [7].

While underexposure of voriconazole may decrease the efficacy, overexposure increases the risk primarily for neural and hepatic toxicity [8,9]. Unitil now, no universally applicable therapeutic range has been established. Two Japanese societies in 2013 recommended voriconazole trough concentrations of $>1-2 \mathrm{mg} / \mathrm{L}$ for clinical efficacy and of $<4-5 \mathrm{mg} / \mathrm{L}$ for hepatic tolerability [10], while the British Society for Medical Mycology in 2014 recommended trough concentrations of $>1 \mathrm{mg} / \mathrm{L}$ for efficacy and of $<4-6 \mathrm{mg} / \mathrm{L}$ for safety [11]. The Chinese Pharmacological Society recommended $0.5 \mathrm{mg} / \mathrm{L}$ as the lower limit and $5 \mathrm{mg} / \mathrm{L}$ as the upper limit of the voricoanzole trough concentration range [12]. In 2017, the Third Fungal Diagnosis and Management of Aspergillus diseases Clinical Guideline recommended a trough concentration range of $1-5.5 \mathrm{mg} / \mathrm{L}$ for most patients with voriconazole prophylaxis or treatment while the range for patients with severe infections be 2 to 6 $\mathrm{mg} / \mathrm{L}$ [4]. In the present project, we selected lower and upper trough concentrations of $>1-2 \mathrm{mg} / \mathrm{L}$ and $<5-6$ $\mathrm{mg} / \mathrm{L}$, respectively.

Voriconazole is extensively metabolized via the cytochrome P450 enzymes CYP2C19 and CYP3A4 [13], slightly by CYP2C9 and flavin-containing monooxygenase (FMO) [14], while less than $2 \%$ is excreted renally as the parent drug [15-17]. The main metabolite in plasma was reported as voriconazole $\mathrm{N}$-oxide, accounting for $72 \%$ of circulating metabolites [1]. However, Geist et al. found that voriconazole N-oxide and its conjugates excreted in urine within $12 \mathrm{~h}$ during steady-state only accounted for $1 \%$ of the administered dose, while other metabolites, i.e., dihydroxy fluoropyrimidine-voriconazole and hydroxy fluoropyrimidine-voriconazole together with their conjugates accounted for $14 \%$ and $3 \%$, respectively [17]. This was in agreement with another study where the major metabolite excreted in urine over $96 \mathrm{~h}$ was dihydroxy fluoropyrimidine-voriconazole, accounting for $13 \%$ of the administered dose of voriconazole [18]. Therefore, it seems reasonable to also consider dihydroxy-fluoropyrimidine voriconazole and hydroxy-fluoropyrimidine voriconazole as major metabolites of voriconazole, although both have low plasma concentrations due to their high renal clearances, which was reported to be approximately 150 -fold and 55 -fold higher, respectively, than that of voriconazole Noxide [17]. However, two other groups found that the the main metabolite of voriconazole excreted in urine within $48 \mathrm{~h}$ after administration was voriconazole $\mathrm{N}$-oxide with 10 to $21 \%$ the administered dose $[15,16]$. The discrepancies between the studies may be explained by the length of urine collection periods together with a different elimination half-life of the metabolites and the mechanism-based inhibition (MBI) of CYP3A4. Thus, both fluoropyrimidine hydroxylation and $\mathrm{N}$-oxidation pathways were considered as the main metabolic pathways, mainly mediated by CYP3A4 and CYP2C19, as shown in Figure 1. 
Genetic polymorphisms of CYP2C19 are a major source for inter-individual variability, as reflected by 3-fold higher $\mathrm{C}_{\max }$ values and 2- to 5-fold higher AUC values in CYP2C19 poor metabolizers (PMs) compared to those in normal metabolizers (NMs) or rapid metabolizers (RMs) [7,19,20].

Furthermore, voriconazole is also an inhibitor of CYP3A4 and 2C19 [21]. In vitro, voriconazole $K_{i}$ for the competitive inhibition of CYP3A4-mediated metabolism of midazolam was reported to range from 0.15 to 0.66 $\mu \mathrm{M}[21,22]$. In vivo, oral administration of therapeutic dosages of voriconazole increased the AUC of midazolam to $940 \%$ and $353 \%$ by oral and intravenous co-administration, respectively [23]. Also, voriconazole was reported to exhibit "autoinhibition" on CYP3A4 in vivo [15,24]. In addition, to properly describe the respective processes concerning enzyme inhibition by voriconazole in vivo, "time-dependent inhibition" and "autoinhibition" of voriconazole were integrated into the models reported by Friberg et al. and Kim et al., respectively [25,26].

Therefore, we investigated the inhibition of voriconazole and its metabolite voriconazole N-oxide on CYP3A4 and CYP2C19 in vitro. Based on the in vitro assay results, a whole-body physiologically-based pharmacokinetic (PBPK) model of voriconazole incorporating CYP3A4 MBI was then developed to describe dose- and timedependent pharmacokinetics in the different CYP2C19 genotypes. Finally, model-based simulations were carried out to i) elaborate potentially exposure-equivalent dosing regimens for CYP2C19 genotype groups; ii) assess the dynamic inhibition of CYP3A4 by voriconazole in the liver and small intestine; iii) further evaluate drug-drug interactions (DDIs) between voriconazole and other CYP3A4 probe substrates. An early stage of this work has been presented in the Population Approach Group in Europe conference [27].

\section{MATERIALS AND METHODS}

\subsection{In vitro assay for inhibition of CYP2C19 and CYP3A4}

The in vitro assay for inhibition of human CYP2C19 and CYP3A4 by voriconazole and its metabolite voriconazole $\mathrm{N}$-oxide, together with the respective measurements and data analysis were carried out according to the methods reported in the supplementary materials.

\subsection{Model development}

The PBPK model for voriconazole was developed by combining bottom-up and top-down approaches. An extensive literature search was performed to obtain (a) drug physio-chemical properties, (b) pharmacokinetic parameters describing absorption, distribution, metabolism and excretion processes and (c) clinical studies of intravenous and oral administration of voriconazole to healthy subjects with different dosing regimens. The clinical studies were screened and selected according to the following criteria: (i) intravenous or oral administration of voriconazole, (ii) healthy volunteers, (iii) plasma concentration-time profiles of voriconazole were available, and (iv) articles published in English. The training dataset for model development was selected based on (i) the information required for each step of model development, (ii) the optimized parameters, (iii) the number of studies available and (iv) the informative property of profiles for individual studies (genotype groups, dosing regimens, and routes of administration), as shown in Figure 2. Except datasets required and used for model development, all the remaining clinical trials datasets were utilized for model evaluation.

The modeling software PK-Sim ${ }^{\circledR}$ (version 7.3.0, part of the Open Systems Pharmacology suite) was used for model development, which consists of a system- and a drug-dependent component. System-dependent 
physiological parameters (organ volumes, blood flow rates, hematocrit, etc.) were provided in PK-Sim ${ }^{\circledR}$ with the small molecule model [28-30]. Demographic characteristics of subjects were taken from each clinical study. Drug-specific physicochemical properties were obtained from the literature. Organ-plasma partition coefficients were determined by the Poulin and Theil method based on both the literature [31] and the best overlap between observed and predicted concentration-time profiles.

The workflow of model development is presented in Figure 2. For model development, the simplifying assumption was made that the metabolism of voriconazole is mediated exclusively by CYP3A4 and CYP2C19; the minor contributions of CYP2C9, FMOs and unchanged renal elimination of voriconazole were neglected $[13,16]$. Tissue expression distribution of enzymes was provided by the PK-Sim ${ }^{\circledR}$ expression database based on reverse transcription-polymerase chain reaction (RT-PCR) profiles [32] together with the reference value of 4.32 $\mu \mathrm{mol} \mathrm{CYP3A4}$ and $0.76 \mu \mathrm{mol}$ CYP2C19 per liter liver tissue [33]. The relative CYP2C19 expression for different genotypes was obtained based on the CYP2C19 protein content ratio in genotype-defined pooled human liver microsomes [34]. The metabolism process of voriconazole was described by Michaelis-Menten kinetics [35]. As reported by Damle et al. [31], $K_{m}$ for CYP3A4 and CYP2C19 were set to 15 and $3.5 \mu \mathrm{M}$, respectively, and $V_{\max }$ for CYP2C19 was fixed $1.19 \mathrm{pmol} / \mathrm{min} / \mathrm{pmol}$. $V_{\max }$ for CYP3A4 was optimized based on the concentration-time profile in CYP2C19 PMs [18] with the assumption that only CYP3A4 contributes to the metabolism of voriconazole in PMs. MBI was integrated into the model with Eq. S4 in the supplementary materials based on the in vitro inactivity assay results of $K_{I}$. The other parameter $k_{\text {inact }}$ was optimized based on concentration-time curves after multiple intravenous administrations [36], since the in vitro derived $k_{\text {inact }}$ parameter value led to an overprediction of midazolam AUCs when evaluating the voriconazolemidazolam DDI studies.

The specific intestinal permeability was optimized based on the studies, including both intravenous and oral administration of voriconazole $[6,37,38]$. The dissolution of the formulation was assumed to follow a Weibull function and was estimated based on the concentration-time datasets after oral administration [18].

\subsection{Model evaluation}

Model-based simulations were created for visual comparison with the observed concentration-time profiles of voriconazole in different CYP2C19 genotype groups. For clinical trials not reporting CYP2C19 genotype information, the population was assumed to be NM as this genotype is the most common 2C19 polymorphism prevalent in more than 64\% of "white", African American, Hispanic, and Ashkenazi populations [39]. The visual criteria for a good model performance were that $95 \%$ population prediction intervals should cover the observed individual plasma concentration-time profiles from original datasets, or that the observed aggregate plasma concentration-time profiles should be inside the $68 \%$ population prediction intervals. Predicted AUC, $\mathrm{C}_{\max }$, and

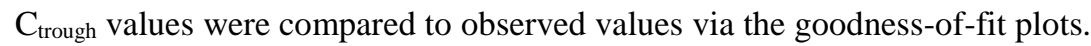

The quantitative evaluation criterion for a good model performance was that the ratios of predicted to observed $\mathrm{AUC}, \mathrm{C}_{\max }$, and $\mathrm{C}_{\text {trough }}$ (trough concentration for multiple doses) values should be within 0.5- to 2.0-fold limits, as shown in Tables 1, 2 and S4. As a quantitative summary of the predictive performance of the model, the geometric mean fold error (GMFE) was calculated with Eq. 1 [40].

Eq. 1 GMFE $=10^{\left(\sum \log _{10}(\operatorname{pred} \mathrm{P} / \text { obs P }) \mid\right) / n}$ 
GMFE: geometric mean fold error of all $\mathrm{AUC}, \mathrm{C}_{\max }$ or $\mathrm{C}_{\text {trough }}$ predictions from the respective model, pred P: predicted parameter (AUC, $\mathrm{C}_{\max }$ or $\mathrm{C}_{\text {trough }}$ ), obs $\mathrm{P}$ : observed parameter (AUC, $\mathrm{C}_{\max }$ or $\mathrm{C}_{\text {trough }}$ ), n: number of studies.

\subsection{Drug-drug interactions with other CYP3A4 substrates}

Published PBPK models of the CYP3A4 probe substrates midazolam or alfentanil were integrated with the model of voriconazole to assess the inhibitory effects of voriconazole on CYP3A4 in vivo and to verify the inhibition model of voriconazole meanwhile [40]. The DDI modeling performance was evaluated by both visual comparison of predicted versus observed probe substrates pharmacokinetic profiles, and by calculation of DDI $\mathrm{AUC}$ ratios and $\mathrm{C}_{\max }$ ratios according to Eq. 2-3.

Eq. 2 DDI AUC ratio $=\frac{A_{U C} \text { treatment }}{A U C_{\text {reference }}}$

Eq. 3 DDI $C_{\max }$ ratio $=\frac{C_{\text {maxtreatment }}}{C_{\text {max }} \text { reference }}$

AUC (or $\mathrm{C}_{\max }$ ) treatment: AUC (or $\mathrm{C}_{\max }$ ) of victim drug with voriconazole co-treatment; $\mathrm{AUC}$ (or $\mathrm{C}_{\max }$ ) reference: AUC (or $\mathrm{C}_{\max }$ ) for victim drug administration alone.

\subsection{Sensitivity Analysis}

According to Eq. 4, the ratio of the relative change of $\mathrm{AUC}_{\mathrm{T}}$ (area under the plasma concentration-time curve during a dosage interval $(\tau)$ ) versus the relative alteration of the evaluated parameter was calculated at steadystate after the standard therapeutic multiple dosages of voriconazole by oral administration. The sensitivity analysis was also conducted for the DDI between voriconazole and midazolam. Parameters selected for the sensitivity analysis fulfilled one of the following criteria [40]: i) optimized; ii) related to optimized parameters; iii) a strong influence on calculation methods used in the model; iv) significant impact in the model.

Eq. $4 \mathrm{~S}=\frac{\Delta \mathrm{AUC}}{\mathrm{AUC}} \div \frac{\Delta p}{p}$

S: sensitivity of AUC to the evaluated parameter; $\triangle \mathrm{AUC}$ : change of AUC; AUC: AUC with the initial value; $\Delta \mathrm{p}$ : change of the assessed parameter value; $\mathrm{p}$ : parameter with the initial value. A sensitivity value of +1.0 means that a $10 \%$ change of the examined parameter causes a $10 \%$ alteration of the predicted $\mathrm{AUC}_{\mathrm{T}}$.

\subsection{Virtual population characteristics}

Based on the demographic characteristics from each clinical trial, virtual populations of 100 individuals were generated to assess the variability of the predicted concentration-time profiles quantitatively from the respective clinical trials. Information on age, body weight, body height and proportions of female participants was entered into the software for each clinical trial. The default population variabilities for enzyme expression in PK-Sim ${ }^{\circledR}$ were used. To compare the variability of observed and simulated pharmacokinetic profiles, $68 \%$ population prediction intervals (approx. mean $\pm \mathrm{SD}$ in case of assumed normal distribution) were plotted if the observed concentration-time profiles were reported as mean $( \pm \mathrm{SD})$; while $95 \%$ population prediction intervals were described when all individual concentration-time profiles were available [41]. 


\subsection{Model Applications}

211 First, model-based simulations were performed according to the dosing regimens of the clinical trials in Table 1

212 to compare the predicted versus observed data, capturing the nonlinear pharmacokinetics of voriconazole 213 including dose- and time-dependence. Second, different CYP2C19 genotype groups, i.e., RMs, NMs, IMs

214 (intermediate metabolizers) and PMs were simulated respectively to depict the effect of genetic polymorphisms

215 of CYP2C19 on the metabolism of voriconazole in Table 2. Then, based on the PBPK model we explored the 216 performance of various maintenance doses in different CYP2C19 genotype groups (RMs, NMs, and IMs).

217 Virtual populations of 1000 individuals were generated based on the summary demographic characteristics from

218 all clinical trials. The simulated dosing regimens were $400 \mathrm{mg}$ b.i.d on the first day followed by $100-400 \mathrm{mg}$

219 b.i.d on the following days for two weeks, which was considered to be sufficient to achieve steady-state. The

220 probability of target attainment and potentially toxic trough concentrations was calculated based on two different

221 definitions of therapeutic ranges to reflect the heterogeneity of guidelines. Thus, a therapeutic target of at least

2221 or $2 \mathrm{mg} / \mathrm{L}$ and at most 5 or $6 \mathrm{mg} / \mathrm{L}$ was defined. Third, the time course of active CYP3A4 content in both liver

223 and small intestine during voriconazole treatment was simulated based on the most frequent oral therapeutic

224 dosing regimen of voriconazole, i.e., $400 \mathrm{mg}$ b.i.d on the first day and then $200 \mathrm{mg}$ b.i.d on the following days.

225 Fourth, by connecting the PBPK models of midazolam (or alfentanil) and voriconazole, DDIs models between

226 voriconazole and the victim drugs was set up (see Table 3). 


\section{RESULTS}

\subsection{In vitro assays}

The result of the $\mathrm{IC}_{50}$ shift assays indicated that voriconazole caused MBI on CYP3A4, with a 16-fold difference in the absence and presence of NADPH (see Table 4), supporting MBI to be introduced into the PBPK model. In contrast, inhibition of CYP2C19 was only within a 2-/3-fold range of $\mathrm{IC}_{50}$ shift and therefore was considered as negligible during model development. The inactivation kinetic assay gave a $K_{I}$ of 9.33 (95\% CIs: 2.56-34.0) $\mu \mathrm{M}$ and a $k_{\text {inact }}$ of 0.0428 (95\% CIs: $\left.0.0171-0.107\right) \mathrm{min}^{-1}$ for CYP3A4, which were used for the parametrization in the PBPK model (see Table 5).

\subsection{Model development and evaluation}

\subsubsection{Clinical studies}

Among all 93 concentration-time profiles of voriconazole from clinical trials, 21 were used for the model development and 72 for model evaluation (see Tables 1 and 2). The participants were all healthy volunteers, with an age range from 18 to 53 years and a body weight from 47 to $103 \mathrm{~kg}$. CYP2C19 genotypes included 62 RMs (" $\left.1 /{ }^{*} 17,{ }^{*} 17 / /^{*} 17\right), 101 \mathrm{NMs}\left({ }^{*} 1 / /^{*} 1\right), 77 \mathrm{IMs}\left({ }^{*} 1 /{ }^{*} 2,{ }^{*} 1 /{ }^{*} 3,{ }^{*} 2 /{ }^{*} 17,{ }^{*} 2 /{ }^{*} 2 /{ }^{*} 17\right)$, and $65 \mathrm{PMs}\left({ }^{*} 2 /{ }^{*} 2,{ }^{*} 2 / * 3,{ }^{*} 3 /{ }^{*} 3\right)$ (see Table 2). Administration protocols included both oral and intravenous routes, both single and multiple doses, and individual doses ranging from 1.5 to $6 \mathrm{mg} / \mathrm{kg}$ and from 50 to $400 \mathrm{mg}$.

\subsubsection{Model development}

$V_{\text {max }}$ for CYP3A4 was originally fixed to 0.31 according to the reported value by Damle et al. [31]. However, simulations resulted in a more than two-fold over-prediction for AUC for low doses of voriconazole. The reasons for over-prediction of AUC were explored. Simultaneous and separate optimization of $V_{\text {max }}$ for CYP3A4 and CYP2C19 showed that the optimized value for CYP2C19 was approaching to the reported one, while for CYP3A4, the optimized value was far higher than the reported one. A possible reason was that the reported value for CYP3A4 was obtained without consideration of MBI on CYP3A4, which might lead to underestimation of $V_{\max }$. Furthermore, the subjects in the clinical studies belonged to different CYP2C19 genotypes, which provided the possibility to optimize $V_{\max }$ of CYP3A4. Therefore, this parameter was optimized as $2.12 \mathrm{pmol} / \mathrm{min} / \mathrm{pmol}$ based on the concentration-time datasets of CYP2C19 PMs with intravenous administration [18], assuming that only CYP3A4 mediated the metabolism of voriconazole in PMs due to the deficiency of CYP2C19. For other genotypes, both CYP2C19 and CYP3A4 contributed in the metabolism of voriconazole. The different CYP2C19 genotypes were integrated into the model for RMs, NMs, IM or PM with the reference CYP2C19 expression values of $0.79,0.76,0.40$, and $0.01 \mu \mathrm{mol} / \mathrm{L}$, respectively [34]. Therefore, in the absence of evidence for another root cause of AUC over-prediction,

MBI of CYP3A4 by voriconazole was introduced into the model with Eq. S4 based on the in vitro inactivation kinetic parameter $K_{I}$ of $9.33 \mu \mathrm{M}$. When the in vitro $k_{\text {inact }}$ of $0.0428 \mathrm{~min}^{-1}$ served as model input, the predicted concentration-time profiles of midazolam in DDI with co-treatment of voriconazole were overestimated. Therefore, $k_{\text {inact }}$ was finally optimized as $0.015 \mathrm{~min}^{-1}$ based on the concentration-time profiles with multiple intravenous dosing of voriconazole [36]. 


\subsubsection{Model evaluation}

The input parameters describing the PBPK model of voriconazole are listed in Table 6. The predicted pharmacokinetic results for the respective clinical trials in comparison with the observed aggregate values are presented in Tables $\mathbf{1}$ and 2, together with administration protocols and subjects' details. Prediction performance of the model was quantitatively evaluated by the ratios of predicted versus observed aggregate AUC and $\mathrm{C}_{\max }$ with calculated GMFEs shown in Tables 1 and 2. Among the 28 test datasets for subjects with unspecified genotype, $71 \%$ of predicted/observed aggregate $\mathrm{AUC}$ ratios and all aggregate $\mathrm{C}_{\max }$ ratios were within 0.5- to 2.0fold limits (Table 1). Taking genotype of CYP2C19 into consideration, from 44 test profiles, $89 \%$ of aggregate AUC ratios and all aggregate $C_{\max }$ ratios were within 0.5- to 2.0-fold (Table 2). Also, $85 \%$ of predicted/observed aggregate $C_{\text {trough }}$ ratios from clinical trials after multiple administration were within the 0.5- to 2.0-fold range (Table S4). The performance of the model was visualized by comparing predicted and observed concentrationtime profiles as shown in Figures 3-4 and S1-2, S4-7. The model-based simulations for multiple doses captured the dose- and time-dependent non-linear pharmacokinetics of voriconazole well (Figure 3 and S1, S4, S7). Although the population predictions for low doses (i.e., $50 \mathrm{mg}$ ) reflected over-estimation compared to the observed individual data, for the therapeutic dose of $400 \mathrm{mg}$ the $95 \%$ prediction interval covered the variability of the observed individual data sufficiently (Figures 4 and S5), indicating that simulations grouped by different CYP2C19 genotype were suitable to describe the effect of genetic polymorphisms of CYP2C19 on the metabolism of voriconazole. This was further confirmed by the good population prediction for the observed aggregate concentration-time profiles for both a single and multiple doses in different CYP2C19 genotype groups, despite an over-prediction of exposure for multiple doses in PMs (Figure S2 and S7). Also, plotting predicted versus observed AUC, $\mathrm{C}_{\max }$ and $\mathrm{C}_{\text {trough }}$ from all the clinical studies confirmed a good fit of the final PBPK model of voriconazole for most clinical trials (Figure 5), despite an over-prediction of AUC for low doses.

\subsection{Sensitivity analysis}

A sensitivity analysis was performed based on the simulation of the therapeutic multiple oral dosing regimen (400 mg b.i.d on the first day and then $200 \mathrm{mg}$ b.i.d on the following days until steady-state) to assess the impact of the parameters on the model. It was shown that the voriconazole model was most sensitive to CYP2C19 $k_{c a t}$, $K_{m}$, and fraction unbound values (all taken from the literature) with sensitivity values ranging from -1.08 to 0.75 (Figure S3A).

The sensitivity analysis of the parameters for DDI models between voriconazole and midazolam on the $\mathrm{AUC}_{0-\mathrm{t}}$ of [23] exhibited that sensitivity was most pronounced for midazolam lipophilicity, CYP3A4 $k_{\text {inact }}$ and $K_{I}$ with the sensitivity values beyond -1.0 or 1.0 (Figure S3B).

\subsection{Model application}

\subsubsection{Suitable maintenance doses in CYP2C19 genotype groups}

A separate simulation of specific CYP2C19 genotype groups could accurately describe both observed individual and aggregate concentration-time profiles for either a single dose or for multiple doses, as assessed by the respective criteria (Table 2, Figure 3 and S2, S5, S7). Therefore, model-based simulations were carried out to 
explore the performance of voriconazole maintenance doses for different CYP2C19 genotypes (Figure 8). The standard dosage (oral $400 \mathrm{mg}$ twice daily on the first day and $200 \mathrm{mg}$ twice daily for the following days) was confirmed to be appropriate for IMs; while for RMs and NMs, the $200 \mathrm{mg}$ maintenance dose seems to be insufficient. The model-based simulation suggests to double the maintenance dose for RMs and NMs to increase the probability of target attainment two-fold while maintaining a probability of toxic concentrations below $20 \%$.

305 The less reliable prediction for multiple doses in PMs precludes the suggestion of an appropropriate maintenance dose regimen in PMs, although it clearly shows that the $200 \mathrm{mg}$ bid dose is too high.

\subsubsection{Inhibition of CYP3A4 by voriconazole}

The time courses of CYP3A4 activity in both liver and small intestine were assessed during chronic voriconazole treatment. The maximum inhibition was reached at $51.2 \mathrm{~h}$ in the liver and $52.5 \mathrm{~h}$ in the small intestine (Figure 6), resulting from the combination of the physiological CYP3A4 turnover and MBI of CYP3A4 (Eq. S4). The CYP3A activity was predicted to recover $90 \%$ of its baseline 5 days after the last voriconazole dose.

\subsubsection{DDI modeling}

313 The CYP3A4 inhibition model of voriconazole was further applied to the DDI between CYP3A4 probe 314 substrates as victims (midazolam and alfentanil) and voriconazole as the perpetrator. Figure 7 and S8 demonstrate the good performance of DDI PBPK models for voriconazole and the two probe substrates. The observed AUC change of substrates during treatment with voriconazole versus control was inside the $90 \%$ confidence interval of the predicted AUC change, and the predicted/observed DDI AUC ratio of alfentanil was 0.86 , indicating that this inhibition model was appropriate. The inhibition model was further confirmed to be suitable by the predicted/observed midazolam DDI AUC ratios of 1.09 and 0.76 , respectively, for intravenous and oral administration. 


\section{DISCUSSION}

A whole-body PBPK model of voriconazole integrating MBI of CYP3A4 has been successfully developed. Model-based simulations of voriconazole plasma concentrations were in good agreement with observations from clinical studies with both intravenous and oral administration of a wide range of single and multiple doses. The model was also appropriate to predict voriconazole plasma concentrations for individual CYP2C19 genotype groups and the extent of DDIs with the CPY3A4 probe substrates midazolam and alfentanil caused by voriconazole.

An MBI effect of voriconazole on its metabolism in vivo was reported previously [15,25]. Several lines of evidence supported that the incorporation of MBI should be considered to describe the pharmacokinetics of voriconazole accurately. First, Mikus et al. proposed that "autoinhibition" of CYP3A was the key to explain the observed dose nonlinearity of voriconazole elimination after administration of 50 and $400 \mathrm{mg}$ in healthy volunteers $[15,24]$. Second, time-dependent disproportionately increasing exposure of voriconazole was found in vivo after multiple doses; e.g., AUC for multiple intravenous administration $\left(3 \mathrm{mg} \mathrm{kg} \mathrm{kg}^{-1}\right.$ over 1 hour once on the first day and b.i.d. on the following days) on the $5^{\text {th }}$ day of treatment was more than 2-fold higher than the predicted value based on the results for the first dose under the assumption of dose-linearity and continued to increase until the $12^{\text {th }}$ day doses [36]. Third, both Friberg et al. and Kim et al. integrated "time-dependent inhibition" and "autoinhibtion" models of voriconazole to describe the respective processes concerning enzyme inhibition by voriconazole in vivo, respectively [25,26]. Fourth, our in vitro assays clearly showed a pronounced $\mathrm{IC}_{50}$ shift from 48.7 to $3 \mu \mathrm{M}$, verifying MBI of CYP3A4 by voriconazole. Indeed, incorporation of MBI into the PBPK model turned out to be essential to predict the dose- and time-dependent pharmacokinetic nonlinearity of voriconazole.

Beyond MBI, reversible inhibition of CYP3A4 and CYP2C19 by voriconazole was also explored. Our in vitro assay resulted in a competitive inhibition of CYP3A4 $K_{i}$ of 0.47 (95\% CIs: $\left.0.344-0.636\right) \mu \mathrm{M}$, which is in agreement with results from other studies, e.g., competitive $\left(K_{i}=0.66 \mu \mathrm{M}\right)$ and noncompetitive inhibition $\left(K_{i}=\right.$ $2.97 \mu \mathrm{M})$ in one study [21]; and solely competitive inhibition $\left(K_{i}=0.15 \mu \mathrm{M}\right)$ in another study [22]. But in vivo evaluation of DDIs between voriconazole and midazolam indicated that assumption of a simple competitive inhibition only was explicitly not sufficient in vivo [42]. An MBI model of CYP3A was discussed in the previous research but not incorporated due to lack of in vitro data to support it. At that time, a hypothetical extra effect compartment was introduced to describe a time delay. Thus, we conducted an in vitro assay to explore MBI of voriconazole on CYP3A4 to fully understand the metabolism of voriconazole.

Also, our in vitro assay resulted in the competitive inhibition of voriconazole on CYP2C19 with $K_{i}$ values of 1.08 (95\% CIs: $0.815-1.43) \mu \mathrm{M}$ and 1.26 (95\% CIs: 0.839-1.82) $\mu \mathrm{M}$ with omeprazole and mephenytoin as substrates, respectively (in Table 4), which could provide some evidence for DDI between voriconazole and CYP2C19 probe substrates (e.g., omeprazole and mephenytoin). In vivo, voriconazole was reported to increase the $\mathrm{C}_{\max }$ and $\mathrm{AUC}_{\mathrm{T}}$ of omeprazole by $116 \%$ and $280 \%$ [43], respectively. However, detailed in vivo data were not available, which limited the evaluation of the PBPK DDI models between voriconazole and CYP2C19 substrates, which is one of the limitations of our PBPK model. 
Beyond the effects of the parent drug, the inhibition of voriconazole N-oxide on CYP3A4 and CYP2C19 was also investigated. Although voriconazole N-oxide exhibited reversible inhibition on both enzymes, the effects were weaker with $K_{i} 0.894$ (95\% CIs: 0.650-1.22) and 9.00 (95\% CIs: 6.94-11.7) $\mu \mathrm{M}$, respectively (see Table 4).

361

362

363 Additionally, at therapeutic voriconazole doses, plasma concentrations of voriconazole N-oxide typically reach only about a third compared to that of its parent drug [17]. Thus, the inhibition by voriconazole N-oxide would be much less than that of the parent drug and was considered negligible during PBPK model development.

The advantages of the PBPK model approach presented here become evident compared to an empirical population pharmacokinetic model. PBPK models can depict a more precise mechanistic picture of inhibition processes. Based on the developed PBPK model, it was feasible to describe the time course of inhibition of CYP3A4 during and after voriconazole treatment by taking into account the dynamic nature of the inhibition process with a clear differentiation between liver and small intestinal enzyme activity (Figure 6). Furthermore, this PBPK model could be applied to predict the effect of voriconazole dosing schemes on several other CYP3A4 substrate drugs and thus to manage respective clinical DDIs. It was verified by the observation that the predicted DDI was mostly suitable for oral and intravenous midazolam as well as for alfentanil (Figure 7 and S8), both being established CYP3A4 probe substrates [44].

For a thorough understanding of voriconazole pharmacokinetics, CYP2C19 genotype groups were another important factor during model development, since the wide inter-individual variability mainly resulted from the genotypes of CYP2C19. Therefore, suitable maintenance doses for CYP2C19 genotype groups (RMs, NMs, and IMs) were suggested based on simulations. For PMs, the search for a dose to provide an appropriate exposure was less reliable due to the limited performance of the model for multiple doses in PMs. With MBI on CYP3A4 and deficiency of CYP2C19, voriconazole would accumulate in PMs and might reach extremely high concentrations after multiple administrations. Yet, the observations from one study showed that the increase of voriconazole concentrations in PMs after multiple doses was not as high as the prediction (Figure S2 f)[19], indicating that other elimination pathway may compensate to prevent drug accumulation in the body. However, for PMs, the experimental data to quantitatively describe voriconazole pharmacokinetics in individuals were sparse, limiting the integration of more complex pathways.

Although the presented model performed well in several ways, it has several limitations. The first one is the assumption that only CYP3A4 and CYP2C19 mediate primary metabolism and elimination of voriconazole. This assumption may result in over-estimation of the role of CYP3A4 and CYP2C19 activity; the consequence of ignoring FMO and CYP2C9, however, should be acceptable in most CYP2C19 genotypes (RMs, NMs, and IMs). $K_{m}$ values for FMO1 and FMO3 are in the millimolar range (about $3 \mathrm{mM}$ ) [14], which is far beyond the concentrations reached in vivo. A contribution of CYP2C9 was identified in only one paper [13] with a small $V_{\max }$ value, which was not confirmed in other in vitro assays [13,45]. Renal excretion of unchanged voriconazole is less than $2 \%$, and primary metabolism by glucuronidation is also negligible [17]. Thus, it is reasonable to simplify the primary metabolism of voriconazole as depending on CYP3A4 and 2C19 only. Also, the fact that our model was able to properly describe most published data supports a role of CYP3A4 and CYP2C19 also for unknown metabolic pathways. Another limitation was that the inhibitory effect of voriconazole N-oxide with less inhibitory effect and lower plasma concentrations was not taken into account, as well as the other metabolites. Also, we did not attempt to simultaneously describe the concentration-time profiles of voriconazole N-oxide and other metabolites (hydroxy-fluoropyrimidine voriconazole and dihydroxy-fluoropyrimidine 
voriconazole) reported in a few published datasets to limit the complexity of the model and to limit the number of assumptions required. The third limitation was that during the model development, datasets with low doses, e.g., $50 \mathrm{mg}$, were not successfully integrated into the model. When extrapolating the model predictions to low dosages, the simulation showed some over-prediction of voriconazole concentrations. However, such low doses are not clinically relevant. Fourth, the uncertainty of $K_{I}$ from in vitro assays could not be implemented into the PBPK model due to technical limitations of the software. Although the current model successfully described the complex metabolism of voriconazole, we suggest to further verify the model by additional clinical studies (e.g., studies quantifying the metabolites of voriconazole, i.e., voriconazole $\mathrm{N}$-oxide, hydroxy-fluoropyrimidine voriconazole and dihydroxy-fluoropyrimidine voriconazole in plasma/urine/feces; and studies in PMs with low multiple doses; DDI studies between CYP3A4 substrates and voriconazole including quantification of its metabolites and different routes of administration of both substrates and voriconazole). 


\section{CONCLUSION}

410 MBI of CYP3A4 by voriconazole is an important pharmacokinetic characteristic of the drug and needs to be 411 taken into account along with CYP2C19 genotype to predict the exposure of voriconazole properly. By 412 incorporating these elements, a PBPK model of voriconazole was developed which could accurately capture the 413 time- and dose-dependent alterations of voriconazole pharmacokinetics as well as DDIs caused by voriconazole 414 inhibitory effects on CYP3A4. This model could support individual dose optimization of voriconazole as well as 415 DDI risk management. It will be provided as a public tool in the Open Systems Pharmacology (OSP) repository 416 (http://www.open-systems-pharmacology.org/) to assess the DDI potential of investigational drugs, to support 417 the design of clinical trials or to expand the model for predictions in special populations.

\section{Compliance with Ethical Standards}

\section{$420 \quad$ Funding}

421 X.L. obtained financial support provided by the program of China Scholarship Council during the study and 422 manuscript preparation (No.201406920024). T.I.S. obtained a governmental research grant (\#13821) from the 423 Hospital District of South-West Finland, Finland to support his work.

\section{Conflict of interest}

425 Sebastian Frechen is an employee and potential shareholder of Bayer AG, Leverkusen, Germany. Xia Li, 426 Daniel Moj, Thorsten Lehr, Max Taubert, Chih-hsuan Hsin, Gerd Mikus, Pertti J. Neuvonen, Klaus T. Olkkola, 427 Teijo I. Saari, Uwe Fuhr have no conflicts of interest to declare. 


\section{References}

1. U S Food and Drug Administration. Pfizer Label: voriconazole for injection, tablets, oral suspension: LAB0271-12. 2005.

2. Herbrecht R, Denning DW, Patterson TF, Bennett JE, Greene RE, Oestmann J-W, et al. Voriconazole versus amphotericin B for primary therapy of invasive aspergillosis. N Engl J Med. 2002;347:408-15.

3. Misch EA, Safdar N. Updated guidelines for the diagnosis and management of aspergillosis. J Thorac Dis. 2016;8:E1771-6.

4. Ullmann AJ, Aguado JM, Arikan-Akdagli S, Denning DW, Groll AH, Lagrou K, et al. Diagnosis and management of Aspergillus diseases: executive summary of the 2017 ESCMID-ECMM-ERS guideline. Clin Microbiol Infect. 2018;24:e1-38.

5. Theuretzbacher U, Ihle F, Derendorf H. Pharmacokinetic/pharmacodynamic profile of voriconazole. Clin Pharmacokinet. 2006;45:649-63.

6. Purkins L, Wood N, Ghahramani P, Greenhalgh K, Allen MJ, Kleinermans D. Pharmacokinetics and safety of voriconazole following intravenous- to oral-dose escalation regimens. Antimicrob Agents Chemother. 2002;46:2546-53.

7. Owusu Obeng A, Egelund EF, Alsultan A, Peloquin CA, Johnson JA. CYP2C19 polymorphisms and therapeutic drug monitoring of voriconazole: are we ready for clinical implementation of pharmacogenomics? Pharmacotherapy. 2014;34:703-18.

8. Pascual A, Calandra T, Bolay S, Buclin T, Bille J, Marchetti O. Voriconazole therapeutic drug monitoring in patients with invasive mycoses improves efficacy and safety outcomes. Clin Infect Dis. 2008;46:201-11.

9. Jin H, Wang T, Falcione BA, Olsen KM, Chen K, Tang H, et al. Trough concentration of voriconazole and its relationship with efficacy and safety: a systematic review and meta-analysis. J Antimicrob Chemother. 2016;71:1772-85.

10. Hamada Y, Tokimatsu I, Mikamo H, Kimura M, Seki M, Takakura S, et al. Practice guidelines for therapeutic drug monitoring of voriconazole: a consensus review of the Japanese Society of Chemotherapy and the Japanese Society of Therapeutic Drug Monitoring. J Infect Chemother. 2013;19:381-92.

11. Ashbee HR, Barnes RA, Johnson EM, Richardson MD, Gorton R, Hope WW. Therapeutic drug monitoring (TDM) of antifungal agents: guidelines from the British Society for Medical Mycology. J Antimicrob Chemother. 2014;69:1162-76.

12. Chen K, Zhang X, Ke X, Du G, Yang K, Zhai S. Individualized medication of voriconazole: a practice guideline of the division of therapeutic drug monitoring, Chinese pharmacological society. Ther Drug Monit. 2018;40:663-74.

13. Hyland R, Jones BC, Smith DA. Identification of the cytochrome P450 enzymes involved in the N-oxidation of voriconazole. Drug Metab Dispos. 2003;31:540-7. 
14. Yanni SB, Annaert PP, Augustijns P, Bridges A, Gao Y, Benjamin DK, et al. Role of flavin-containing monooxygenase in oxidative metabolism of voriconazole by human liver microsomes. Drug Metab Dispos. 2008;36:1119-25.

15. Hohmann N, Kreuter R, Blank A, Weiss J, Burhenne J, Haefeli WE, et al. Autoinhibitory properties of the parent but not of the $\mathrm{N}$-oxide metabolite contribute to infusion rate-dependent voriconazole pharmacokinetics. Br J Clin Pharmacol. 2017;83:1954-65.

16. Roffey SJ, Cole S, Comby P, Gibson D, Jezequel SG, Nedderman ANR, et al. The disposition of voriconazole in mouse, rat, rabbit, guinea pig, dog, and human. Drug Metab Dispos. 2003;31:731-41. 17. Geist MJP, Egerer G, Burhenne J, Riedel K-D, Weiss J, Mikus G. Steady-state pharmacokinetics and metabolism of voriconazole in patients. J Antimicrob Chemother. 2013;68:2592-9.

18. Scholz I, Oberwittler H, Riedel K-D, Burhenne J, Weiss J, Haefeli WE, et al. Pharmacokinetics, metabolism and bioavailability of the triazole antifungal agent voriconazole in relation to CYP2C19 genotype. Br J Clin Pharmacol. 2009;68:906-15.

19. Lee S, Kim B-H, Nam W-S, Yoon SH, Cho J-Y, Shin S-G, et al. Effect of CYP2C19 polymorphism on the pharmacokinetics of voriconazole after single and multiple doses in healthy volunteers. J Clin Pharmacol. 2012;52:195-203.

20. Weiss J, ten Hoevel MM, Burhenne J, Walter-Sack I, Hoffmann MM, Rengelshausen J, et al. CYP2C19 genotype is a major factor contributing to the highly variable pharmacokinetics of voriconazole. J Clin Pharmacol. 2009;49:196-204.

21. Jeong S, Nguyen PD, Desta Z. Comprehensive in vitro analysis of voriconazole inhibition of eight cytochrome P450 (CYP) enzymes: major effect on CYPs 2B6, 2C9, 2C19, and 3A. Antimicrob Agents Chemother. 2009;53:541-51.

22. Yamazaki H, Nakamoto M, Shimizu M, Murayama N, Niwa T. Potential impact of cytochrome P450 3A5 in human liver on drug interactions with triazoles. Br J Clin Pharmacol. 2010;69:593-7.

23. Saari T, Laine K, Leino K, Valtonen M, Neuvonen P, Olkkola K. Effect of voriconazole on the pharmacokinetics and pharmacodynamics of intravenous and oral midazolam. Clin Pharmacol Ther. 2006;79:362-70.

24. Hohmann N, Kocheise F, Carls A, Burhenne J, Weiss J, Haefeli WE, et al. Dose-dependent bioavailability and CYP3A Inhibition contribute to non-linear pharmacokinetics of voriconazole. Clin Pharmacokinet. 2016;55:1535-45.

25. Friberg LE, Ravva P, Karlsson MO, Liu P. Integrated population pharmacokinetic analysis of voriconazole in children, adolescents, and adults. Antimicrob Agents Chemother. 2012;56:3032-42.

26. Kim Y, Rhee S-J, Park WB, Yu K-S, Jang I-J, Lee S. A personalized CYP2C19 phenotype-guided dosing regimen of voriconazole using a population pharmacokinetic analysis. J Clin Med. 2019;8:227-41. 
27. Li X, Frechen S, Moj D, Taubert M, Hsin C, Mikus G, et al. A Physiologically-Based Pharmacokinetic Model of Voriconazole. Popul Approach Gr Eur. 2019;ISSN 1871-6032; Abstr 8995.

28. Davies B, Morris T. Physiological parameters in laboratory animals and humans. Pharm Res. 1993;10:10935.

29. Edginton AN, Schmitt W, Willmann S. Development and evaluation of a generic physiologically based pharmacokinetic model for children. Clin Pharmacokinet. 2006;45:1013-34.

30. Mordenti J. Man versus beast: pharmacokinetic scaling in mammals. J Pharm Sci. 1986;75:1028-40.

31. Damle B, Varma M V, Wood N. Pharmacokinetics of voriconazole administered concomitantly with fluconazole and population-based simulation for sequential use. Antimicrob Agents Chemother. 2011;55:51727.

32. Meyer M, Schneckener S, Ludewig B, Kuepfer L, Lippert J, Weinstein S. Using expression data for quantification of active processes in physiologically based pharmacokinetic modeling. Drug Metab Dispos. 2012;40:892-901.

33. Rodrigues AD. Integrated cytochrome P450 reaction phenotyping: attempting to bridge the gap between cDNA-expressed cytochromes P450 and native human liver microsomes. Biochem Pharmacol. 1999;57:465-80.

34. Shirasaka Y, Chaudhry AS, McDonald M, Prasad B, Wong T, Calamia JC, et al. Interindividual variability of CYP2C19-catalyzed drug metabolism due to differences in gene diplotypes and cytochrome P450 oxidoreductase content. Pharmacogenomics J. 2016;16:375-87.

35. Michaelis L, Menten ML, Johnson KA, Goody RS. The original Michaelis constant: translation of the 1913 Michaelis-Menten paper. Biochemistry. 2011;50:8264-9.

36. Purkins L, Wood N, Greenhalgh K, Eve MD, Oliver SD, Nichols D. The pharmacokinetics and safety of intravenous voriconazole-a novel wide-spectrum antifungal agent. Br J Clin Pharmacol. 2003;56:2-9.

37. Purkins L, Wood N, Kleinermans D, Love ER. No clinically significant pharmacokinetic interactions between voriconazole and indinavir in healthy volunteers. Br J Clin Pharmacol. 2003;56 Suppl 1:62-8.

38. Purkins L, Wood N, Kleinermans D, Greenhalgh K, Nichols D. Effect of food on the pharmacokinetics of multiple-dose oral voriconazole. Br J Clin Pharmacol. 2003;56:17-23.

39. Strom CM, Goos D, Crossley B, Zhang K, Buller-Burkle A, Jarvis M, et al. Testing for variants in CYP2C19: population frequencies and testing experience in a clinical laboratory. Genet Med. 2012;14:95-100. 40. Hanke N, Frechen S, Moj D, Britz H, Eissing T, Wendl T, et al. PBPK models for CYP3A4 and P-gp DDI prediction: a modeling network of rifampicin, itraconazole, clarithromycin, midazolam, alfentanil, and digoxin. CPT Pharmacometrics Syst Pharmacol. 2018;7:647-59.

41. European Medicines Agency. Guideline on the reporting of physiologically based pharmacokinetic (PBPK) modelling and simulation. 13 December 2018 EMA/CHMP/458101/2016. 
42. Frechen S, Junge L, Saari TI, Suleiman AA, Rokitta D, Neuvonen PJ, et al. A semiphysiological population pharmacokinetic model for dynamic inhibition of liver and gut wall cytochrome P450 3A by voriconazole. Clin Pharmacokinet. 2013;52:763-81.

43. Donnelly JP, De Pauw BE. Voriconazole — a new therapeutic agent with an extended spectrum of antifungal activity. Clin Microbiol Infect. 2004;10:107-17.

44. Fuhr U, Hsin C, Li X, Jabrane W, Sörgel F. Assessment of pharmacokinetic drug-drug interactions in humans: in vivo probe substrates for drug metabolism and drug transport revisited. Annu Rev Pharmacol Toxicol. 2019;59:507-36.

45. Schulz J, Kluwe F, Mikus G, Michelet R, Kloft C. Novel insights into the complex pharmacokinetics of voriconazole: a review of its metabolism. Drug Metab Rev. 2019;1-49.

46. Chung H, Lee H, Han H, An H, Lim KS, Lee Y, et al. A pharmacokinetic comparison of two voriconazole formulations and the effect of CYP2C19 polymorphism on their pharmacokinetic profiles. Drug Des Devel Ther. 2015;9:2609-16.

47. Purkins L, Wood N, Greenhalgh K, Allen MJ, Oliver SD. Voriconazole, a novel wide-spectrum triazole: oral pharmacokinetics and safety. Br J Clin Pharmacol. 2003;56 Suppl 1:10-6.

48. Wood N, Tan K, Purkins L, Layton G, Hamlin J, Kleinermans D, et al. Effect of omeprazole on the steadystate pharmacokinetics of voriconazole. Br J Clin Pharmacol. 2003;56 Suppl 1:56-61.

49. Keirns J, Sawamoto T, Holum M, Buell D, Wisemandle W, Alak A. Steady-state pharmacokinetics of micafungin and voriconazole after separate and concomitant dosing in healthy adults. Antimicrob Agents Chemother. 2007;51:787-90.

50. Liu P, Foster G, Gandelman K, LaBadie RR, Allison MJ, Gutierrez MJ, et al. Steady-state pharmacokinetic and safety profiles of voriconazole and ritonavir in healthy male subjects. Antimicrob Agents Chemother. 2007;51:3617-26.

51. Purkins L, Wood N, Ghahramani P, Kleinermans D, Layton G, Nichols D. No clinically significant effect of erythromycin or azithromycin on the pharmacokinetics of voriconazole in healthy male volunteers. Br J Clin Pharmacol. 2003;56:30-6.

52. Purkins L, Wood N, Kleinermans D, Nichols D. Histamine H2-receptor antagonists have no clinically significant effect on the steady-state pharmacokinetics of voriconazole. Br J Clin Pharmacol. 2003;56 Suppl $1: 51-5$.

53. Purkins L, Wood N, Ghahramani P, Love ER, Eve MD, Fielding A. Coadministration of voriconazole and phenytoin: pharmacokinetic interaction, safety, and toleration. Br J Clin Pharmacol. 2003;56 Suppl 1:37-44.

54. Marshall WL, McCrea JB, Macha S, Menzel K, Liu F, van Schanke A, et al. Pharmacokinetics and tolerability of letermovir coadministered with azole antifungals (posaconazole or voriconazole) in healthy subjects. J Clin Pharmacol. 2018;58:897-904. 
55. Liu P, Foster G, LaBadie RR, Gutierrez MJ, Sharma A. Pharmacokinetic interaction between voriconazole and efavirenz at steady state in healthy male subjects. J Clin Pharmacol. 2008;48:73-84.

56. Andrews E, Damle BD, Fang A, Foster G, Crownover P, LaBadie R, et al. Pharmacokinetics and tolerability of voriconazole and a combination oral contraceptive co-administered in healthy female subjects. Br J Clin Pharmacol. 2008;65:531-9.

57. Damle B, LaBadie R, Crownover P, Glue P. Pharmacokinetic interactions of efavirenz and voriconazole in healthy volunteers. Br J Clin Pharmacol. 2008;65:523-30.

58. Dodds Ashley ES, Zaas AK, Fang AF, Damle B, Perfect JR. Comparative pharmacokinetics of voriconazole administered orally as either crushed or whole tablets. Antimicrob Agents Chemother. 2007;51:877-80.

59. Kakuda TN, Van Solingen-Ristea R, Aharchi F, Smedt G De, Witek J, Nijs S, et al. Pharmacokinetics and short-term safety of etravirine in combination with fluconazole or voriconazole in HIV-negative volunteers. J Clin Pharmacol. 2013;53:41-50.

60. Dowell JA, Schranz J, Baruch A, Foster G. Safety and pharmacokinetics of coadministered voriconazole and anidulafungin. J Clin Pharmacol. 2005;45:1373-82.

61. Wang G, Lei H, Li Z, Tan Z, Guo D, Fan L, et al. The CYP2C19 ultra-rapid metabolizer genotype influences the pharmacokinetics of voriconazole in healthy male volunteers. Eur J Clin Pharmacol. 2009;65:281-5.

62. Mikus G, Schöwel V, Drzewinska M, Rengelshausen J, Ding R, Riedel KD, et al. Potent cytochrome P450 2C19 genotype-related interaction between voriconazole and the cytochrome P450 3A4 inhibitor ritonavir. Clin Pharmacol Ther. 2006;80:126-35.

63. Rengelshausen J, Banfield M, Riedel K, Burhenne J, Weiss J, Thomsen T, et al. Opposite effects of shortterm and long-term St John's wort intake on voriconazole pharmacokinetics. Clin Pharmacol Ther. 2005;78:2533.

64. Lei H-P, Wang G, Wang L-S, Ou-yang D, Chen H, Li Q, et al. Lack of effect of ginkgo biloba on voriconazole pharmacokinetics in Chinese volunteers identified as CYP2C19 poor and extensive metabolizers. Ann Pharmacother. 2009;43:726-31.

65. Zhu L, Brüggemann RJ, Uy J, Colbers A, Hruska MW, Chung E, et al. CYP2C19 genotype-dependent pharmacokinetic drug interaction between voriconazole and ritonavir-boosted atazanavir in healthy subjects. $\mathrm{J}$ Clin Pharmacol. 2017;57:235-46.

66. Saari TI, Laine K, Leino K, Valtonen M, Neuvonen P, Olkkola KT. Voriconazole, but not terbinafine, markedly reduces alfentanil clearance and prolongs its half-life. Clin Pharmacol Ther. 2006;80:502-8. 
Table 1 Clinical studies without information on CYP2C19 genotype used for voriconazole model development and evaluation

\begin{tabular}{|c|c|c|c|c|c|c|c|c|c|c|c|c|c|}
\hline Dose [mg] & Route & $\mathbf{n}$ & $\begin{array}{c}\text { Male } \\
{[\%]}\end{array}$ & $\begin{array}{c}\text { Age } \\
\text { [years] }\end{array}$ & $\begin{array}{c}\text { Weight } \\
\text { [kg] }\end{array}$ & $\begin{array}{c}\text { Use of } \\
\text { dataset }\end{array}$ & $\begin{array}{c}\text { Pred AUC } \\
{\left[\mathrm{mg}{ }^{*} \mathrm{~h} / \mathrm{L}\right]}\end{array}$ & $\begin{array}{l}\text { Obs AUC } \\
{\left[\mathrm{mg} *^{*} \mathbf{h} / \mathrm{L}\right]}\end{array}$ & $\begin{array}{c}\text { Pred/Obs } \\
\text { AUC }\end{array}$ & $\begin{array}{c}\text { Pred } C_{\max } \\
{[\mathrm{mg} / \mathrm{L}]}\end{array}$ & $\begin{array}{c}\text { Obs } C_{\max } \\
{[\mathrm{mg} / \mathrm{L}]}\end{array}$ & $\begin{array}{c}\text { Pred/Obs } \\
\text { C }_{\max }\end{array}$ & Ref \\
\hline 3/kg,QD D1 & $\operatorname{iv}(1 \mathrm{~h})$ & 9 & 100 & $24(20-31)$ & $72(60-87)$ & $\mathrm{d} / \mathrm{a}$ & 7.90 & 5.22 & 1.51 & 2.45 & 2.14 & 1.14 & [36] \\
\hline $\begin{array}{c}\text { 3/kg,BID D3-11.5 } \\
\text { (3/kg,QD D1) }\end{array}$ & $\operatorname{iv}(1 \mathrm{~h})$ & 9 & 100 & $24(20-31)$ & $72(60-87)$ & $\mathrm{d} / \mathrm{a}$ & 16.7 & 16.5 & 1.01 & 3.54 & 3.62 & 0.98 & [36] \\
\hline 6/kg, BID D1 & $\operatorname{iv}(1 \mathrm{~h})$ & 9 & 100 & $28(19-41)$ & $73(66-80)$ & $\mathrm{d} / \mathrm{a}$ & 16.2 & 13.2 & 1.23 & 5.12 & 4.70 & 1.09 & [36] \\
\hline $\begin{array}{c}\text { 3/kg,BID D2-9.5 } \\
(6 / \mathrm{kg}, \mathrm{BID} \text { D1) }\end{array}$ & iv(1h) & 9 & 100 & $28(19-41)$ & $73(66-80)$ & $\mathrm{d} / \mathrm{a}$ & 15.2 & 13.3 & 1.14 & 3.39 & 3.06 & 1.11 & [36] \\
\hline $\begin{array}{l}\text { 3/kg,BID D2-7 } \\
\text { (6/kg BID D1) }\end{array}$ & $\operatorname{iv}(1 \mathrm{~h})$ & 14 & 100 & $26.5 \pm 1.48 *$ & $78.7 \pm 1.93^{*}$ & $\mathrm{~d} / \mathrm{a}$ & 17.3 & 13.9 & 1.24 & 3.64 & 3.00 & 1.21 & [6] \\
\hline $\begin{array}{c}\text { 200,BID D8-13.5 } \\
\text { (6/kg, BID D1, } \\
\text { 3/kg,BID D2-7) }\end{array}$ & po(-) & 14 & 100 & $26.5 \pm 1.48^{*}$ & $78.7 \pm 1.93 *$ & $\mathrm{~d} / \mathrm{a}$ & 13.7 & 9.77 & 1.40 & 2.17 & 1.89 & 1.15 & [6] \\
\hline $\begin{array}{l}\text { 4/kg,BID D2-7 } \\
\text { (6/kg BID D1) }\end{array}$ & iv(1h) & 7 & 100 & $24.7 \pm 2.37^{*}$ & $73.2 \pm 2.12 *$ & $\mathrm{~d} / \mathrm{a}$ & 34.4 & 29.5 & 1.17 & 5.82 & 5.40 & 1.08 & [6] \\
\hline $\begin{array}{c}\text { 300,BID D8-13.5 } \\
\text { (6/kg BID D1, } \\
\text { 4/kg,BID D2-7) }\end{array}$ & po(-) & 7 & 100 & $24.7 \pm 2.37 *$ & $73.2 \pm 2.12 *$ & $d / a$ & 20.6 & 30.9 & 0.67 & 2.95 & 4.84 & 0.61 & [6] \\
\hline $\begin{array}{l}\text { 5/kg,BID D2-7 } \\
\text { (6/kg BID D1) }\end{array}$ & iv(1h) & 14 & 100 & $26.5 \pm 1.48^{*}$ & $78.7 \pm 1.93^{*}$ & $\mathrm{~d} / \mathrm{a}$ & 44.5 & 43.4 & 1.03 & 7.46 & 7.18 & 1.04 & [6] \\
\hline $\begin{array}{c}\text { 400,BID D8-13.5 } \\
\text { (6/kg BID D1, } \\
5 / \mathrm{kg}, \mathrm{BID} \text { D2-7) }\end{array}$ & po(-) & 14 & 100 & $26.5 \pm 1.48^{*}$ & $78.7 \pm 1.93^{*}$ & $\mathrm{~d} / \mathrm{a}$ & 31.8 & 37.6 & 0.85 & 4.48 & 5.27 & 0.85 & [6] \\
\hline 100, SIG & $\operatorname{iv}(4 h)$ & 20 & 95 & $32(23-52)$ & $80.8 \pm 11.8^{*}$ & $\mathrm{e} / \mathrm{a}$ & 3.25 & $2.63^{\mathrm{a}}$ & 1.24 & 0.51 & 0.48 & 1.06 & [15] \\
\hline 400, SIG & $\operatorname{iv}(2 h)$ & 20 & 95 & $32(23-52)$ & $80.8 \pm 11.8^{*}$ & $\mathrm{e} / \mathrm{a}$ & 16.5 & $21.1^{\mathrm{a}}$ & 0.78 & 3.14 & 3.73 & 0.84 & [15] \\
\hline 400, SIG & $\operatorname{iv}(4 h)$ & 20 & 95 & $32(23-52)$ & $80.8 \pm 11.8^{*}$ & $\mathrm{e} / \mathrm{a}$ & 16.1 & $18.8^{\mathrm{a}}$ & 0.86 & 2.23 & 2.67 & 0.84 & [15] \\
\hline 400, SIG & $\operatorname{iv}(6 h)$ & 20 & 95 & $32(23-52)$ & $80.8 \pm 11.8^{*}$ & $\mathrm{e} / \mathrm{a}$ & 15.9 & $17.6^{\mathrm{a}}$ & 0.90 & 1.81 & 1.83 & 0.99 & [15] \\
\hline 200, SIG & $\operatorname{iv}(1.5)$ & 52 & 100 & $26.9 \pm 4.9^{*}$ & $70.7 \pm 7.8^{*}$ & $\mathrm{e} / \mathrm{a}$ & 7.53 & $8.13^{\mathrm{a},}$ & 0.93 & 1.91 & $2.14^{\star}$ & 0.89 & [46] \\
\hline 1.5/kg,QD D1 & po(-) & 11 & 100 & $27(20-45)$ & $73(60-90)$ & $\mathrm{e} / \mathrm{a}$ & 2.67 & 0.88 & 3.03 & 0.62 & 0.364 & 1.70 & [47] \\
\hline $\begin{array}{c}\text { 1.5/kg,TID D3-11.5 } \\
(1.5 / \mathrm{kg}, \mathrm{QD} \text { D1) }\end{array}$ & po(-) & 11 & 100 & $27(20-45)$ & $73(60-90)$ & $\mathrm{e} / \mathrm{a}$ & 6.48 & 3.79 & 1.71 & 1.34 & 1.11 & 1.21 & [47] \\
\hline 2/kg,QD D1 & po(-) & 8 & 100 & $26(20-36)$ & $74(66-89)$ & $\mathrm{e} / \mathrm{a}$ & 4.07 & 1.18 & 3.45 & 0.85 & 0.485 & 1.75 & [47] \\
\hline $\begin{array}{c}\text { 2/kg,BID D3-11.5 } \\
(2 / \mathrm{kg}, \mathrm{QD} \text { D1) }\end{array}$ & po(-) & 8 & 100 & $26(20-36)$ & $74(66-89)$ & $\mathrm{e} / \mathrm{a}$ & 9.52 & 4.30 & 2.21 & 1.61 & 1.01 & 1.59 & [47] \\
\hline
\end{tabular}




\begin{tabular}{|c|c|c|c|c|c|c|c|c|c|c|c|c|c|}
\hline 2/kg,QD D1 & po(-) & 8 & 100 & $31(21-44)$ & $74(64-87)$ & $\mathrm{e} / \mathrm{a}$ & 3.46 & 1.44 & 2.40 & 0.82 & 0.646 & 1.27 & [47] \\
\hline $\begin{array}{c}\text { 2/kg,TID D3-11.5 } \\
(2 / \mathrm{kg}, \mathrm{QD} \text { D1) }\end{array}$ & po(-) & 8 & 100 & $31(21-44)$ & $74(64-87)$ & $\mathrm{e} / \mathrm{a}$ & 9.23 & 9.04 & 1.02 & 1.88 & 2.18 & 0.86 & [47] \\
\hline 3/kg,QD D1 & po(-) & 8 & 100 & $25(18-30)$ & $73(61-87)$ & $\mathrm{e} / \mathrm{a}$ & 5.65 & 3.15 & 1.79 & 1.22 & 1.19 & 1.03 & [47] \\
\hline $\begin{array}{c}\text { 3/kg,BID D3-11.5 } \\
\text { (3/kg,QD D1) }\end{array}$ & po(-) & 8 & 100 & $25(18-30)$ & $73(61-87)$ & $\mathrm{e} / \mathrm{a}$ & 15.4 & 11.2 & 1.38 & 2.50 & 2.36 & 1.06 & [47] \\
\hline 4/kg,QD D1 & po(-) & 8 & 100 & $25(20-37)$ & $74(66-94)$ & $\mathrm{e} / \mathrm{a}$ & 7.67 & 5.90 & 1.30 & 1.35 & 1.57 & 0.86 & [47] \\
\hline $\begin{array}{c}\text { 4/kg,QD D3-11.5 } \\
\text { (4/kg,QD D1) }\end{array}$ & po(-) & 8 & 100 & $25(20-37)$ & 74 (66-94) & $\mathrm{e} / \mathrm{a}$ & 14.3 & 13.2 & 1.08 & 1.98 & 2.07 & 0.96 & [47] \\
\hline 200,BID D1-6.5 & po(-) & 9 & 100 & $22(19-25)$ & $74(67-91)$ & $\mathrm{d} / \mathrm{a}$ & 14.4 & 12.9 & 1.12 & 2.40 & 2.24 & 1.07 & [37] \\
\hline 200,BID D1 & po(cap) & 6 & 100 & $29(23-36)$ & $74(67-82)$ & $\mathrm{d} / \mathrm{a}$ & 4.58 & 3.14 & 1.46 & 1.23 & 0.96 & 1.28 & [38] \\
\hline $\begin{array}{c}\text { 200,BID D2-6.5 } \\
(200, \text { BID D1) }\end{array}$ & po(cap) & 6 & 100 & $29(23-36)$ & $74(67-82)$ & $\mathrm{d} / \mathrm{a}$ & 12.0 & $12.5^{\mathrm{a}}$ & 0.96 & 2.20 & 2.04 & 1.08 & [38] \\
\hline 400,QD D1 & po(-) & 18 & 100 & $26(20-40)$ & $75(66-92)$ & $\mathrm{e} / \mathrm{a}$ & 9.22 & 9.31 & 0.99 & 1.92 & 2.31 & 0.83 & [48] \\
\hline $\begin{array}{c}\text { 200,BID D2-9.5 } \\
(400, \text { QD D1) }\end{array}$ & po(-) & 18 & 100 & $26(20-40)$ & $75(66-92)$ & $\mathrm{e} / \mathrm{a}$ & 12.5 & 11.2 & 1.12 & 2.23 & 2.08 & 1.07 & [48] \\
\hline $\begin{array}{l}\text { 200,BID D2-4 } \\
\text { (400 BID D1) }\end{array}$ & po(-) & 12 & - & $18-50$ & $>40$ & $\mathrm{e} / \mathrm{a}$ & 12.4 & $15.2^{\mathrm{a},}$ & 0.82 & 2.23 & $2.60^{\star}$ & 0.86 & [49] \\
\hline $\begin{array}{c}\text { 200,BID D22-24 } \\
\text { (400 BID D21) }\end{array}$ & po(-) & 12 & - & $18-50$ & $>40$ & $\mathrm{e} / \mathrm{a}$ & 12.0 & $13.6^{\mathrm{a},}$ & 0.88 & 2.21 & $2.50^{\star}$ & 0.88 & [49] \\
\hline $\begin{array}{c}\text { 200,BID D2-2.5 } \\
(400 \text { BID D1) }\end{array}$ & po(tab) & 13 & 100 & $31(19-52)$ & $78(62-88)$ & $\mathrm{e} / \mathrm{a}$ & 13.0 & $26.5^{\mathrm{a},}$ & 0.49 & 2.24 & $3.60^{\star}$ & 0.62 & {$[50]$} \\
\hline $\begin{array}{c}\text { 200,BID D2-2.5 } \\
(400 \text { BID D1) }\end{array}$ & po(tab) & 16 & 100 & $40(26-54)$ & $80(65-95)$ & $\mathrm{e} / \mathrm{a}$ & 13.1 & $26.8^{a}$ & 0.49 & 2.24 & $3.36^{\star}$ & 0.67 & [50] \\
\hline 200,BID D1-6.5 & po(tab) & 10 & 100 & $25(20-30)$ & $73(62-85)$ & $\mathrm{d} / \mathrm{a}$ & 13.1 & 10.5 & 1.25 & 2.32 & 1.87 & 1.24 & [51] \\
\hline 200,BID D1-6.5 & po(-) & 12 & 100 & $29(21-39)$ & $75(67-82)$ & $\mathrm{d} / \mathrm{a}$ & 12.1 & 13.6 & 0.89 & 2.19 & 2.25 & 0.97 & [52] \\
\hline 200,BID D1-6.5 & po(-) & 11 & 100 & $29(20-42)$ & $77(61-91)$ & $\mathrm{d} / \mathrm{a}$ & 12.0 & 9.42 & 1.27 & 2.16 & 2.00 & 1.08 & [53] \\
\hline $\begin{array}{c}\text { 200,BID D2-3.5 } \\
(400 \text { BID D1) }\end{array}$ & po(-) & 14 & 0 & $35(19-51)$ & $74(52-87)$ & $\mathrm{e} / \mathrm{a}$ & 13.5 & $17.6^{\mathrm{a}}$ & 0.77 & 2.32 & 2.80 & 0.83 & [54] \\
\hline $\begin{array}{c}\text { 200,BID D2-2.5 } \\
(400 \text { BID D1) }\end{array}$ & po(tab) & 16 & 100 & $34(20-48)$ & $79(59-92)$ & $\mathrm{e} / \mathrm{a}$ & 13.0 & $26.3^{a, \bullet}$ & 0.49 & 2.22 & $3.06^{\star}$ & 0.73 & [55] \\
\hline $\begin{array}{c}\text { 200,BID D2-3.5 } \\
(400 \text { BID D1) }\end{array}$ & po(-) & 16 & 0 & $26(19-36)$ & - & $\mathrm{e} / \mathrm{a}$ & 18.5 & $14.9^{\star}$ & 1.24 & 2.91 & $2.64^{\star}$ & 1.10 & [56] \\
\hline $\begin{array}{c}\text { 200,BID D2-3.5 } \\
(400 \text { BID D1) }\end{array}$ & po(-) & 16 & 100 & $30(20-42)$ & - & $\mathrm{e} / \mathrm{a}$ & 12.6 & $24.0^{\star}$ & 0.53 & 2.10 & $2.74^{\star}$ & 0.77 & [57] \\
\hline
\end{tabular}




\begin{tabular}{|c|c|c|c|c|c|c|c|c|c|c|c|c|c|}
\hline $\begin{array}{c}\text { 200,BID D2-6.5 } \\
\text { (400 BID D1) }\end{array}$ & po(tab) & 20 & 50 & $28(20-43)$ & - & e/a & 12.9 & 11.2 & 1.15 & 2.33 & 2.37 & 0.98 & {$[58]$} \\
\hline $\begin{array}{c}\text { 200,BID D2-7.5 } \\
\text { (400 BID D1) }\end{array}$ & po(-) & 14 & 100 & $29(18-45)$ & - & e/a & 14.6 & $14.7^{\mathrm{a},}$ & 0.99 & 2.47 & $2.87^{\star}$ & 0.86 & {$[59]$} \\
\hline \multirow[t]{3}{*}{$\begin{array}{c}\text { 200,BID D2-3.5 } \\
(400 \text { BID D1) }\end{array}$} & po(-) & 18 & 100 & $28(20-40)$ & - & e/a & 13.2 & $29.9^{\mathrm{b},}$ & 0.44 & 2.25 & $3.96^{\star}$ & 0.57 & {$[60]$} \\
\hline & & & & & & & & GMFE(range) & $1.39(0.44-3.45)$ & & & $1.20(\mathrm{C}$ & .75) \\
\hline & & & & & & & & Pred/Obs within 2-fold & $36 / 44$ & & & $44 / 44$ & \\
\hline
\end{tabular}

AUC values are $\mathrm{AUC}_{\tau}$ if not specified otherwise, ${ }^{\mathrm{a}}$ : $\mathrm{AUC} \mathrm{obs}^{\mathrm{b}}{ }^{\mathrm{b}}$ : $\mathrm{AUC}$ at steady-state; Observed aggregate values are reported as geometric mean if not specified otherwise, $\downarrow$ : arithmetic mean; *: standard error; /kg: per kg of body weight; D: day of treatment according to the numbering in the reference; SIG: single dose, QD: once daily, BID: twice daily, TID: three times daily; iv: intravenously, po: orally; e: datasets for model evaluation, d: dataset for model development; i: individual datasets; a: aggregate datasets; tab: tablet, cap: capsule; Obs: observed aggregate value from literature, Pred: predicted value based on the model; GMFE: geometric mean fold error; -: not available. The ratios of predicted versus observed AUC and $\mathrm{C}_{\max }$ outside 0.5 - to 2.0 -fold limits were printed in bold. 
Table 2 Clinical studies with information on CYP2C19 genotype used for voriconazole model development and evaluation

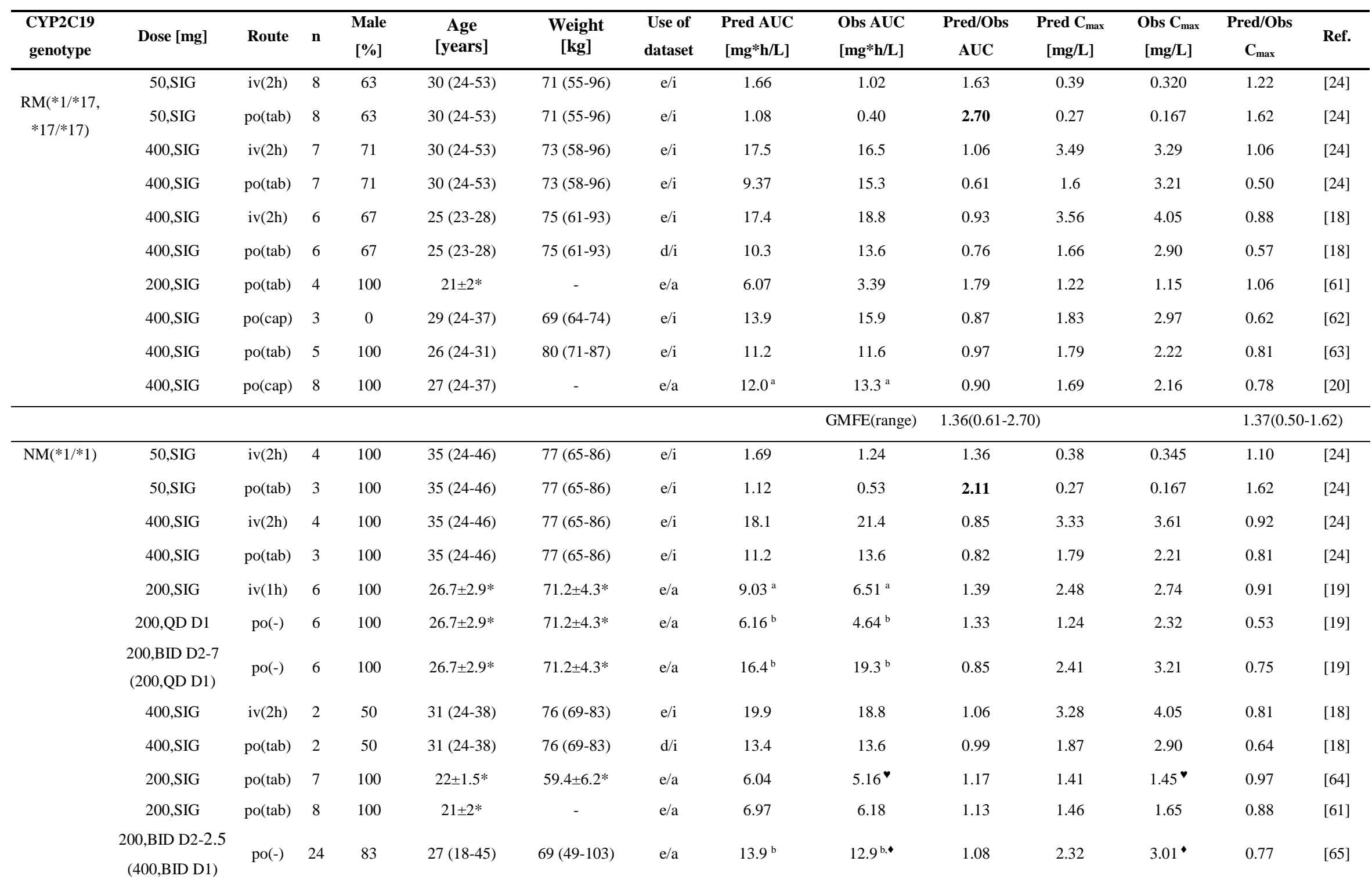




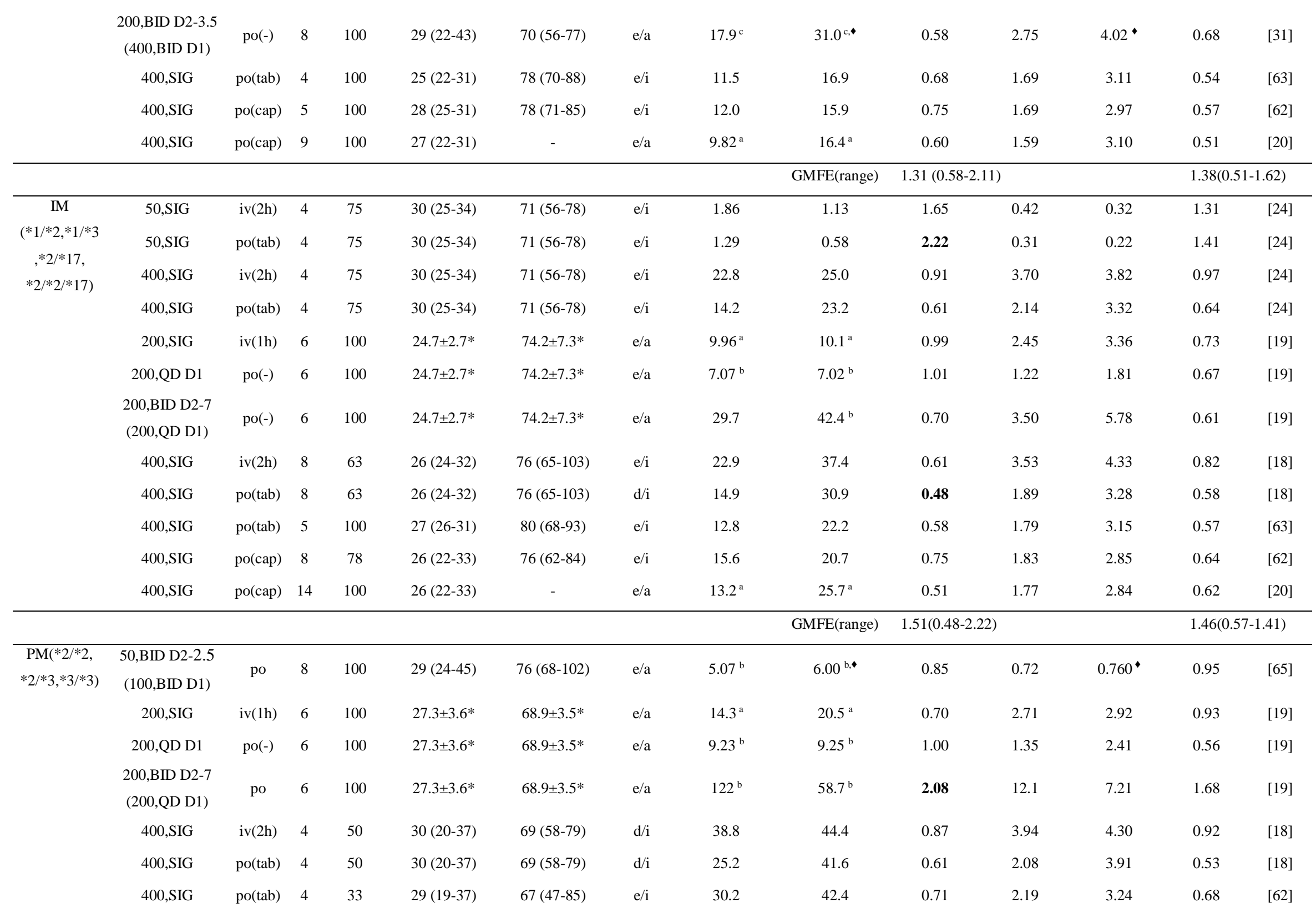




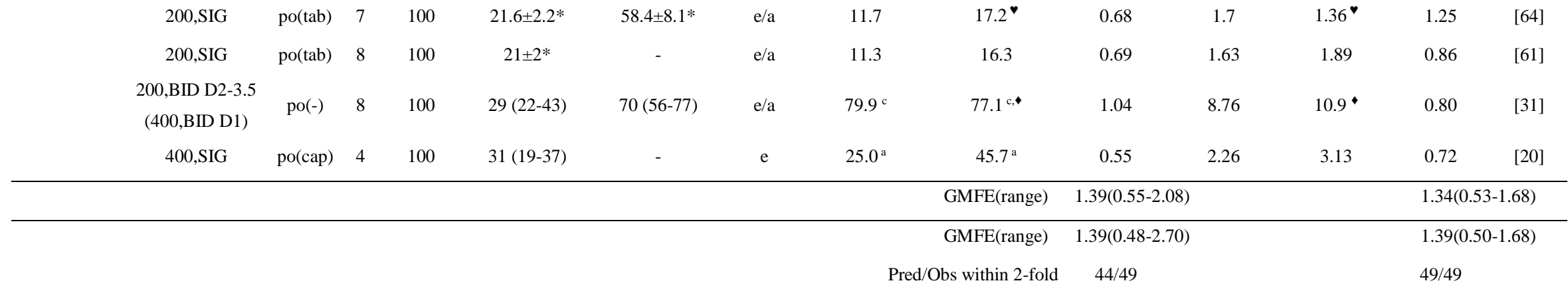

AUC values are $\mathrm{AUC}_{\mathrm{obs}}$ if not specified otherwise, ${ }^{\mathrm{a}}$ : $\mathrm{AUC}_{0-\infty},{ }^{\mathrm{b}}$ : $\mathrm{AUC}_{\tau},{ }^{\mathrm{c}}$ : $\mathrm{AUC}_{12}$. Observed aggregate values are reported as arithmetic mean if not specified otherwise, $\$$ : geometric mean, $\checkmark$ : median; *: standard deviation; D: day of treatment according to the numbering in the reference; SIG: single dose, QD: once a day, BID: twice daily; iv: intravenously, po: orally; e: datasets for model evaluation, d: dataset for model development; i: individual datasets; a: aggregate datasets; Obs: observed aggregate value from literature, Pred: predicted value based on the model; tab: tablet, cap: capsule, GMFE: geometric mean fold error; RM: rapid metabolizers, NM: normal metabolizers, IM: intermediate metabolizers, PM: poor metabolizers; -: not available. The ratios of predicted versus observed AUC and $\mathrm{C}_{\max }$ outside 0.5 - to 2.0-fold limits were printed in bold. 
Table 3 DDI study dosing regimens, populations, predicted and observed AUC and $\mathrm{C}_{\max }$ ratios

\begin{tabular}{|c|c|c|c|c|c|c|c|c|c|c|c|c|c|}
\hline Perpetrator $[\mathrm{mg}]$ & Victim & $\mathbf{n}$ & $\begin{array}{c}\text { Male } \\
{[\%]}\end{array}$ & $\begin{array}{c}\text { Age } \\
\text { [years] }\end{array}$ & $\begin{array}{c}\text { Weight } \\
{[\mathrm{kg}]}\end{array}$ & Use of dataset & $\begin{array}{c}\text { Pred AUC ratio } \\
\text { with/without } \\
\text { VCZ }(90 \% \text { CI })\end{array}$ & $\begin{array}{c}\text { Obs AUC ratio } \\
\text { with/without VCZ } \\
(90 \% \mathrm{CI})\end{array}$ & $\begin{array}{c}\text { Pred AUC ratio } \\
\text { / Obs AUC } \\
\text { ratio }\end{array}$ & $\begin{array}{c}\text { Pred } C_{\max } \text { ratio } \\
\text { with/without } \\
\text { VCZ }(90 \% \\
\text { CI })\end{array}$ & $\begin{array}{c}\text { Obs } \mathrm{C}_{\max } \text { ratio } \\
\text { with/without } \\
\text { VCZ }(90 \% \mathrm{CI})\end{array}$ & $\begin{array}{c}\text { Pred } C_{\max } \\
\text { ratio/Obs } \\
C_{\max } \text { ratio }\end{array}$ & Ref. \\
\hline voriconazole & alfentanil & & & & & & & & & & & & \\
\hline 400 BID D1,200 BID D2,po & $0.02 \mathrm{mg} / \mathrm{kg}, \mathrm{iv}$ & 12 & 58 & $19-31$ & $65-105$ & $\mathrm{e} / \mathrm{a}$ & $3.41(1.69-5.28)$ & $3.97(3.39-4.66)^{\mathrm{a}}$ & 0.86 & - & - & - & {$[61]$} \\
\hline voriconazole & midazolam & & & & & & & & & & & & \\
\hline 400 BID D1,200 BID D2,po & $0.05 \mathrm{mg} / \mathrm{kg}, \mathrm{iv}$ & 10 & 100 & $19-26$ & $65-100$ & $\mathrm{e} / \mathrm{i}$ & $3.95(1.96-6.41)$ & $3.61(3.20-4.08)^{\mathrm{b}}$ & 1.09 & - & - & - & {$[17]$} \\
\hline 400 BID D1,200 BID D2,po & 7.5mg,po & 10 & 100 & $19-26$ & $65-100$ & $\mathrm{e} / \mathrm{i}$ & $7.51(2.83-12.0)$ & $9.85(8.23-11.8)^{\mathrm{b}}$ & 0.76 & $2.44(1.90-3.44)$ & $3.56(2.85-4.44)^{\mathrm{b}}$ & 0.69 & [17] \\
\hline
\end{tabular}

${ }^{\mathrm{a}}$ : $\mathrm{AUC}_{0-10},{ }^{\text {b: }}$ AUC $0-\infty$; Observed aggregated values are reported as geometric mean if not specified otherwise; D: day of treatment according to the numbering in the reference; BID: twice daily; e: datasets for model evaluation, d: dataset for model development; i: individual datasets; a: aggregate datasets; iv: intravenously, po: orally; Obs: observed aggregated value from literature; Pred: predicted value based on the model; CI: confidence interval; -: not available. 
Table $4 \mathrm{IC}_{50}, \mathrm{IC}_{50}$ shift, $K_{i}$ assay results (point estimates with $95 \%$ confidence intervals)

\begin{tabular}{|c|c|c|c|c|c|c|}
\hline \multirow{2}{*}{ Enzyme } & \multirow{2}{*}{ Inhibitor } & \multirow{2}{*}{$\mathrm{IC}_{50}$} & \multirow{2}{*}{$K_{i}$} & \multicolumn{2}{|c|}{$\mathrm{IC}_{50}$} & \multirow{2}{*}{$\mathrm{IC}_{50}$ Shift } \\
\hline & & & & Without NADPH & With NADPH & \\
\hline \multirow{3}{*}{$\begin{array}{c}\text { CYP3A4 } \\
\text { (midazolam) }\end{array}$} & & $\mu M$ & $\mu M$ & \multicolumn{2}{|c|}{$\mu M$} & $\begin{array}{c}\text {-fold } \\
\text { difference }\end{array}$ \\
\hline & VRZ & $6.04(3.41-10.7)$ & $0.470(0.344-0.636)$ & $48.7(18.5-128)$ & $3.00(0.465-19.3)$ & 16 \\
\hline & VRZ N-oxide & $3.52(2.08-5.95)$ & $0.894(0.650-1.22)$ & $32.3(21.1-49.4)$ & $5.24(0.814-33.7)$ & 6 \\
\hline \multirow{2}{*}{$\begin{array}{c}\text { CYP2C19 } \\
\text { (mephenytoin) }\end{array}$} & VRZ & $17.1(11.7-25.0)$ & $1.08(0.815-1.43)$ & $47.6(8.47-267)$ & 24.1(17.6-33.0) & 2 \\
\hline & VRZ N-oxide & 119(49.0-289) & $9.00(6.94-11.7)$ & $145(71.6-295)$ & $44.0(26.8-72.4)$ & 3 \\
\hline \multirow{2}{*}{$\begin{array}{c}\text { CYP2C19 } \\
\text { (omeprazole) }\end{array}$} & VRZ & $5.29(3.98-7.02)$ & $1.26(0.839-1.82)$ & $17.9(11.9-27.1)$ & $5.46(1.10-27.0)$ & 3 \\
\hline & VRZ N-oxide & $40.4(5.78-282)$ & $7.43(5.58-9.80)$ & $121(72.0-202)$ & $21.0(12.6-34.8)$ & 6 \\
\hline
\end{tabular}

The inactivity pre-incubations time was $30 \mathrm{~min}$ and the secondary activity incubation time was $10 \mathrm{~min}$. VRZ: voriconazole. $K_{i}$ : inhibitor constant, $\mathrm{IC}_{50}$ : half maximal inhibitory concentration of inhibitor.

Table 5 Mechanism-based inactivation $K_{I} / k_{\text {inact }}$ assay conditions and results (point estimates with $95 \%$ confidence intervals)

\begin{tabular}{|c|c|c|c|c|c|c|c|}
\hline Enzyme & Substrate & $\begin{array}{c}\text { voriconazole } \\
\text { concentrations } \\
\end{array}$ & $\begin{array}{c}\text { Duration of pre- } \\
\text { incubation }\end{array}$ & $\begin{array}{c}\text { Incubation } \\
\text { time }\end{array}$ & $K_{I}$ & $k_{\text {inact }}$ & $k_{\text {inact }} / K_{I}$ \\
\hline & & $\mu M$ & $\min$ & $\min$ & $\mu M$ & $\min ^{-1}$ & $\mathrm{ml} / \mathrm{min} / \mu \mathrm{mol}$ \\
\hline CYP3A4 & midazolam & $0,4,12,40,120,400$ & $0,1,3,6,12,18,24,30$ & 10 & $\begin{array}{c}9.33 \\
(2.56-34.0) \\
\end{array}$ & $\begin{array}{c}0.0428 \\
(0.0171-0.107) \\
\end{array}$ & 0.00459 \\
\hline
\end{tabular}

$K_{I}$ : the inhibitor concentration when reaching half of $k_{\text {inact }}, k_{\text {inact }}$ : maximum time-dependent inactivation rate constant. 
Table 6 Physicochemical and pharmacokinetic parameters of the voriconazole PBPK model

\begin{tabular}{|c|c|c|c|c|}
\hline Parameter & Units & $\begin{array}{l}\text { Value used in } \\
\text { voriconazole } \\
\text { model }\end{array}$ & Source of values & Description \\
\hline MW & $\mathrm{g} / \mathrm{mol}$ & 349.3 & 349.3 & Molecular weight \\
\hline $\mathrm{fu}$ & $\%$ & $42[1,24,62,63]$ & $0.42[1,24,62,63]$ & Fraction unbound \\
\hline $\log \mathrm{P}$ & & $1.8[24,63]$ & $1.75[64], 1.65 *, 1.8[24,63] 2.56[62]$ & Lipophilicity \\
\hline $\mathrm{pKa}$ & & 1.60 (base) $[65]$ & $\begin{array}{l}1.60[65], 1.76[24,62,63], 12.71 \text { (acidic)*, } \\
2.27 \text { (basic)* }\end{array}$ & Acid dissociation constant \\
\hline Solubility (pH) & $\mathrm{mg} / \mathrm{mL}$ & $\begin{array}{l}3.2(1.0)[65] \\
2.7(1.2)[66] \\
0.1(7.0)^{*}\end{array}$ & $0.2[63], 0.0978^{*}, 3.2(1.0)[65], 2.7(1.2)[66]$ & Solubility \\
\hline $\begin{array}{l}\text { Specific intestinal } \\
\text { permeability }\end{array}$ & $\mathrm{cm} / \mathrm{s}$ & $2.71 * 10^{-4}$ & Optimized, $2.81 * 10^{-5}[24]$ & Normalized to surface area \\
\hline Partition coefficients & & $\begin{array}{l}\text { Poulin and Theil } \\
{[24,62]}\end{array}$ & Poulin and Theil $[24,62]$ & Organ-plasma partition coefficients \\
\hline Cellular permeabilities & & $\begin{array}{l}\text { PK-Sim } \\
\text { standard }\end{array}$ & - & Permeation across cell membranes \\
\hline CYP3A4 $K_{m}$ & $\mu \mathrm{mol} / \mathrm{L}$ & 15 [24] & $\begin{array}{l}15[24], 11[24], 16 \pm 10[67], 11 \pm 3[67] \\
235[8], 834.7 \pm 182.2[63]\end{array}$ & $\begin{array}{l}\text { Michaelis-Menten constant of } \\
\text { CYP3A4 } \#\end{array}$ \\
\hline CYP3A4 $k_{c a t}$ & $\min ^{-1}$ & 2.12 & $\begin{array}{l}\text { Optimized, 0.31[24], } 0.1[24] \\
32.2 \pm 28.4[63], 0.05 \pm 0.01[67] \\
0.10 \pm 0.01[67], 0.14[8]\end{array}$ & CYP3A4 catalytic rate constant ${ }^{\#}$ \\
\hline CYP2C19 $K_{m}$ & $\mu \mathrm{mol} / \mathrm{L}$ & $3.5[24]$ & $3.5[24], 9.3 \pm 3.6[63], 14 \pm 6[67], 3.5[8]$ & $\begin{array}{l}\text { Michaelis-Menten constant of } \\
\text { CYP2C19" }\end{array}$ \\
\hline CYP2C19 $k_{\text {cat }}$ & $\min ^{-1}$ & $1.19[24]$ & $\begin{array}{l}1.19[24], 40 \pm 13.9[63], 0.22 \pm 0.02[67] \\
0.39[8]\end{array}$ & CYP2C19 catalytic rate constant ${ }^{\#}$ \\
\hline GFR fraction & & 1 & - & $\begin{array}{l}\text { Fraction of filtered drug reaching } \\
\text { the urine }\end{array}$ \\
\hline CYP3A4 $K_{I}$ & $\mu \mathrm{mol} / \mathrm{L}$ & 9.33 & in vitro result from this study & $\begin{array}{l}\text { Voriconazole inhibition constant on } \\
\text { CYP3A4 }\end{array}$ \\
\hline CYP3A4 $k_{\text {inact }}$ & $\min ^{-1}$ & 0.015 & $\begin{array}{l}\text { Optimized from in vitro results from this } \\
\text { study }(0.04)\end{array}$ & $\begin{array}{l}\text { Voriconazole inactivation rate } \\
\text { constant on CYP3A4 }\end{array}$ \\
\hline $\mathrm{D}_{\mathrm{T}, 50}$ for tablet & $\min$ & 30 & Optimized & $\begin{array}{l}\text { Dissolution time ( } 50 \% \text { dissolved) } \\
\text { for Weibull function }\end{array}$ \\
\hline Shape factor for tablet & & 1.29 & Optimized & $\begin{array}{l}\text { Dissolution shape parameter for } \\
\text { Weibull function }\end{array}$ \\
\hline
\end{tabular}

* drug bank; all three reported solubility values were used for interpolation; ${ }^{*}$ values apply for global voriconazole metabolism via this enzyme irrespective of the metabolic pathway; Specific intestinal permeability $2.71 * 10^{-4} \mathrm{~cm} / \mathrm{s}$ were optimized; CYP:

cytochrome P450; CYP3A4 $k_{\text {cat }} 2.12 \mathrm{~min}^{-1}$ were optimized; GFR: glomerular filtration rate; -: not available. 


\section{Figure legends}

Figure 1 Metabolic pathway for voriconazole

*Indirect evidence from different CYP2C19 genotype groups [18].

Figure 2 Workflow of voriconazole PBPK model development and evaluation

The PK profiles used to select the distribution model were also utilized to optimize $V_{\max }$ and $k_{\text {inact }}$ for CYP3A4. There were $21 \mathrm{PK}$ datasets for model development and 72 for model evaluation in total. ADME: absorption, distribution, metabolism, elimination; PK: pharmacokinetics; MBI: mechanism-based inactivation; PMs: poor metabolizers; DDIs: drug-drug interactions.

Figure 3 Prediction performance of voriconazole PBPK model on aggregate plasma concentrations for multiple doses

Observed aggregate data reported in the literature are shown as dot, triangle, square, cross, or crossed square [6,36-38,47-60]. Population simulation medians are shown as lines; the shaded areas illustrate the $68 \%$ population prediction intervals. Details of dosing regimens, study populations, predicted versus observed pharmacokinetic parameters are summarized in Table 1. iv: intravenously, po: oral; D: day; QD: once daily, BID: twice daily, TID: three times daily; Plasma conc: voriconazole plasma concentration.

\section{Figure 4 Prediction performance of voriconazole PBPK model on individual plasma concentration in different CYP2C19 genotype groups for a single dose}

Observed individual data reported in the literature are shown as dots [18,24,62,63]. Population simulation medians are shown as lines; the shaded areas illustrate the $95 \%$ population prediction intervals. Details of dosing regimens, study populations, predicted versus observed PK parameters are summarized in Table 2 . iv, intravenously, po: oral; Plasma conc: voriconazole plasma concentration; RM: rapid metabolizers, NM: normal metabolizers, IM: intermediate metabolizers, PM: poor metabolizers; Rengel: Rengelshausen.

Figure 5 Goodness of fit plot of the PBPK model of voriconazole

Predicted versus observed aggregate AUC (a), $\mathrm{C}_{\max }(\mathrm{b})$ and $\mathrm{C}_{\text {trough }}$ (c) of the voriconazole from all clinical studies. The identity line and 0.5- to 2.0-fold acceptance limits are shown as solid and dashed lines, respectively. Different colors represent different clinical trials.

\section{Figure 6 Effect of therapeutic multiple oral dosages of voriconazole on hepatic and small intestinal} CYP3A activity

Predicted change of relative hepatic (green line) and small intestinal (red line) CYP3A activity over time after therapeutic multiple oral dosages of voriconazole. The blue line represents voriconazole plasma concentration. Arrows indicate dosing events of a standard therapeutic dosing schedule for oral voriconazole.

\section{Figure 7 Prediction performance of voriconazole PBPK model in DDI with CYP3A4 probe substrates}

The voriconazole model integrated with the models of CYP3A4 probe substrates predicted inhibitory effects of voriconazole on CYP3A4 in vivo. Population predictions of a) alfentanil or $b$, c) midazolam plasma concentration-time profiles, with and without voriconazole treatment were compared to observed data shown as 
green triangles (control) or red dots (VCZ co-administration) or symbols \pm SD $[23,66]$. Population simulation median are shown as green lines (control) or red lines (VCZ co-administration); the shaded areas illustrate the respective a) $68 \%$ and b, c) $95 \%$ population prediction intervals. iv: intravenously; po: oral. Details of dosing regimens, study populations, predicted and observed DDI AUC ratios and $\mathrm{C}_{\max }$ ratios are summarized in Table 3.

\section{Figure 8 Probability of target attainment for therapeutic and toxic trough concentrations in different CYP2C19 genotype groups for chronic dosing}

Red and green lines represent the probability of therapeutic target attainment based on trough plasma concentration above $1 \mathrm{mg} / \mathrm{L}$ and above $2 \mathrm{mg} / \mathrm{L}$, respectively. Blue and purple lines show probability of toxicity target attainment based on trough plasma concentration above $5 \mathrm{mg} / \mathrm{L}$ and above $6 \mathrm{mg} / \mathrm{L}$, respectively. IM, intermediate metabolizers; NM, normal metabolizers; RM, rapid metabolizers 